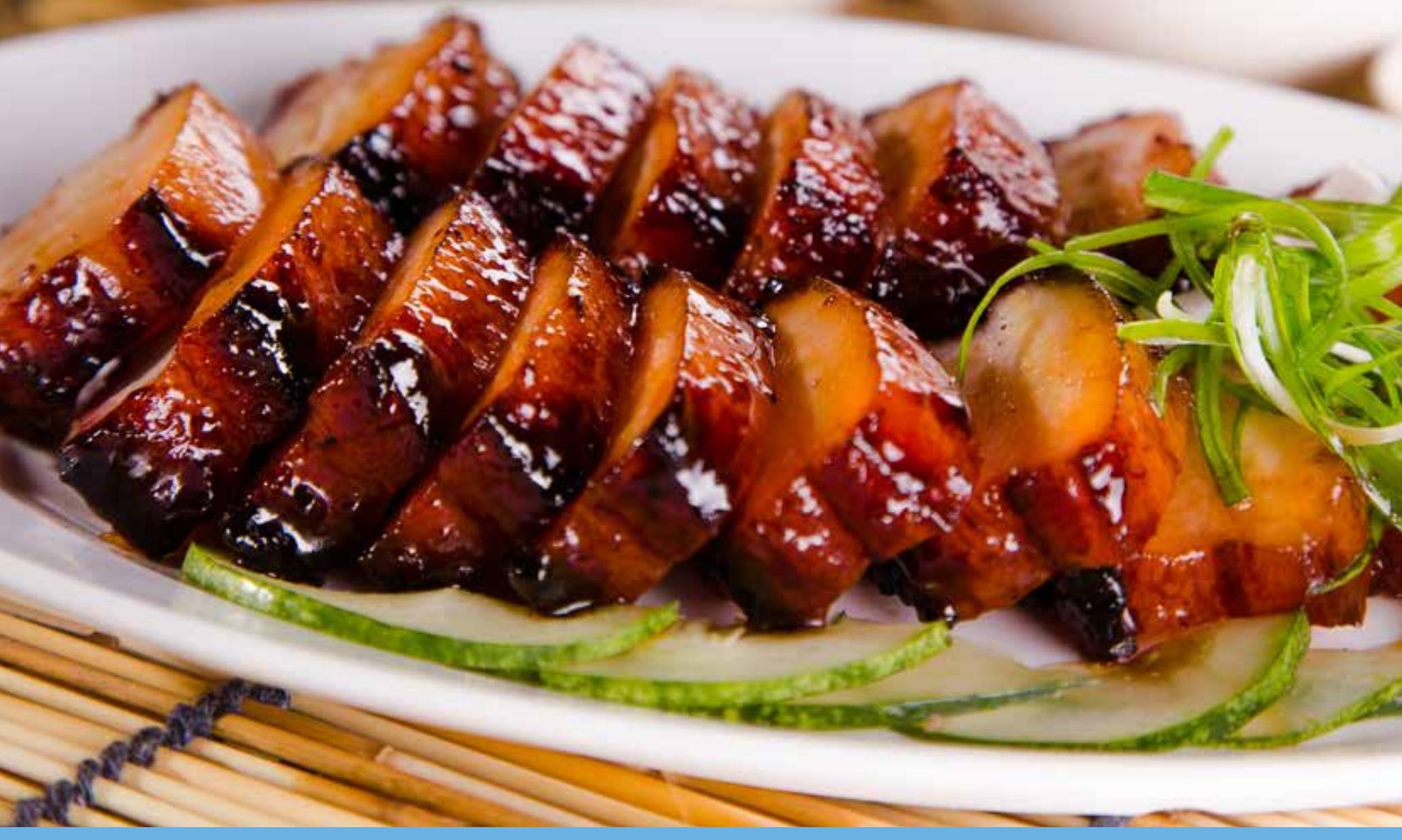

Evaluation of the EU promotion campaign 'Trusted Pork from Europe' 



\section{Evaluation of the EU promotion campaign 'Trusted Pork from Europe'}

R. Hoste, M.A. van Haaster-de Winter and D. Taufik

This research is conducted by Wageningen Economic Research and financed by the Dutch Meat Association.

Wageningen Economic Research

Wageningen, June 2020

REPORT

2020-050

ISBN 978-94-6395-429-7 
R. Hoste, M.A. van Haaster-de Winter and D. Taufik, 2020. Evaluation of the EU promotion campaign 'Trusted Pork from Europe'. Wageningen, Wageningen Economic Research, Report 2020-050. 32 pp.; 12 fig.; 9 tab.; 6 ref.

The Dutch Meat Association has initiated a promotion campaign in order to promote sales of European pig meat in five South East Asian countries. The objectives of the campaign are directed towards creating economic impact and a higher awareness of the different qualities of pig meat from Europe. This study evaluates the campaign by measuring the degree to which these objectives were met.

Key words: Pig meat, EU, competitive position, export, Evaluation, South East Asia

This report can be downloaded for free at https://doi.org/10.18174/524049 or at www.wur.eu/economic-research (under Wageningen Economic Research publications).

(C) 2020 Wageningen Economic Research

P.O. Box 29703, 2502 LS The Hague, The Netherlands, T +31 (0)70 33583 30,

E communications.ssg@wur.nl, http://www.wur.eu/economic-research. Wageningen Economic Research is part of Wageningen University \& Research.

\section{(cc) BY-NC}

This work is licensed under a Creative Commons Attribution-Non Commercial 4.0 International License.

(C) Wageningen Economic Research, part of Stichting Wageningen Research, 2020

The user may reproduce, distribute and share this work and make derivative works from it. Material by third parties which is used in the work and which are subject to intellectual property rights may not be used without prior permission from the relevant third party. The user must attribute the work by stating the name indicated by the author or licensor but may not do this in such a way as to create the impression that the author/licensor endorses the use of the work or the work of the user. The user may not use the work for commercial purposes.

Wageningen Economic Research accepts no liability for any damage resulting from the use of the results of this study or the application of the advice contained in it.

Wageningen Economic Research is ISO 9001:2015 certified.

Wageningen Economic Research Report 2020-050 | Project code 2282100212

Cover photo: Shutterstock 


\section{Contents}

$\begin{array}{ll}\text { Summary } & 5\end{array}$

1

$\begin{array}{ll}\text { Introduction } & 7\end{array}$

$\begin{array}{lll}1.1 & \text { Objective and scope } & 7\end{array}$

1.2 Method 7

1.2.1 Promotion campaign 7

1.2.2 Economic development 9

1.2.3 Level of awareness 9

$2 \quad$ Results: Economic Impact $r$

2.1 Miscellaneous developments 11

2.2 Trade flows 11

$\begin{array}{lll}2.3 & \text { Business opportunities } & 17\end{array}$

3

$\begin{array}{ll}\text { Results: Level of awareness } & 19\end{array}$

3.1 Sample $\quad 19$

3.2 Promotion campaign $\quad 20$

$\begin{array}{lll}3.3 & \text { China } & 21\end{array}$

$\begin{array}{lll}3.4 & \text { Philippines } & 22\end{array}$

$\begin{array}{lll}3.5 & \text { Vietnam } & 23\end{array}$

4 Conclusions and discussion $\quad 25$

$\begin{array}{lll}4.1 & \text { Conclusions } & 25\end{array}$

$\begin{array}{lll}4.2 & \text { Discussion } & 27\end{array}$

$\begin{array}{ll}\text { References and websites } & 29\end{array}$

$\begin{array}{lll}\text { Appendix } 1 & \text { Comext codes and product categories } & 30\end{array}$ 



\section{Summary}

The Dutch Meat Association (COV) has initiated a promotion campaign in order to promote sales of European pig meat in five South East Asian countries and would like to have this EU-funded campaign evaluated. Therefore, they assigned this study. The objectives of the campaign are directed towards creating economic impact and a higher awareness of the different qualities of pig meat from Europe. This study evaluates the campaign by measuring the degree to which these objectives were met. The conclusions are presented below.

Objective 1: Increasing the position of EU pig meat and expansion of the sales assortment The targeted South East Asian countries have gained relevance for EU exporters, especially for frozen meat and offal. We cannot judge whether this is caused by the Trusted Pork from Europe promotion campaign, given the many other factors strongly influencing the world trade of pig meat, especially in the year 2019. The results show an significant increase in the export of EU pig meat to the targeted countries, in particular China. From the analysis it can be concluded that the total export value of pig meat products to the five Asian destination countries has more than doubled over the period 20142019. The total export value amounted to $€ 7 b n$ in 2019, far higher than the $€ 2.5 b n$ in 2014. An export value of $€ 5 \mathrm{bn}$ went to China alone. Also, the relevance of these countries in the EU export portfolio has increased between 2014 and 2019. Sales of muscle meat (frozen and fresh) in 2019 amounted to 2.9 times the value in 2014. In volume terms the lower value products increased 1.8 times, but muscle meat 2.7 times in 2019 compared to 2014. It is concluded that the increased export resulted in a higher share of muscle meat (frozen and fresh) than of lower value products (lard, fat and offal), both in volume and value percentage. This is supported by the interviewees, who state some shift in the sales assortment: increasingly muscle products (category frozen) are being sold, but also offal are well demanded.

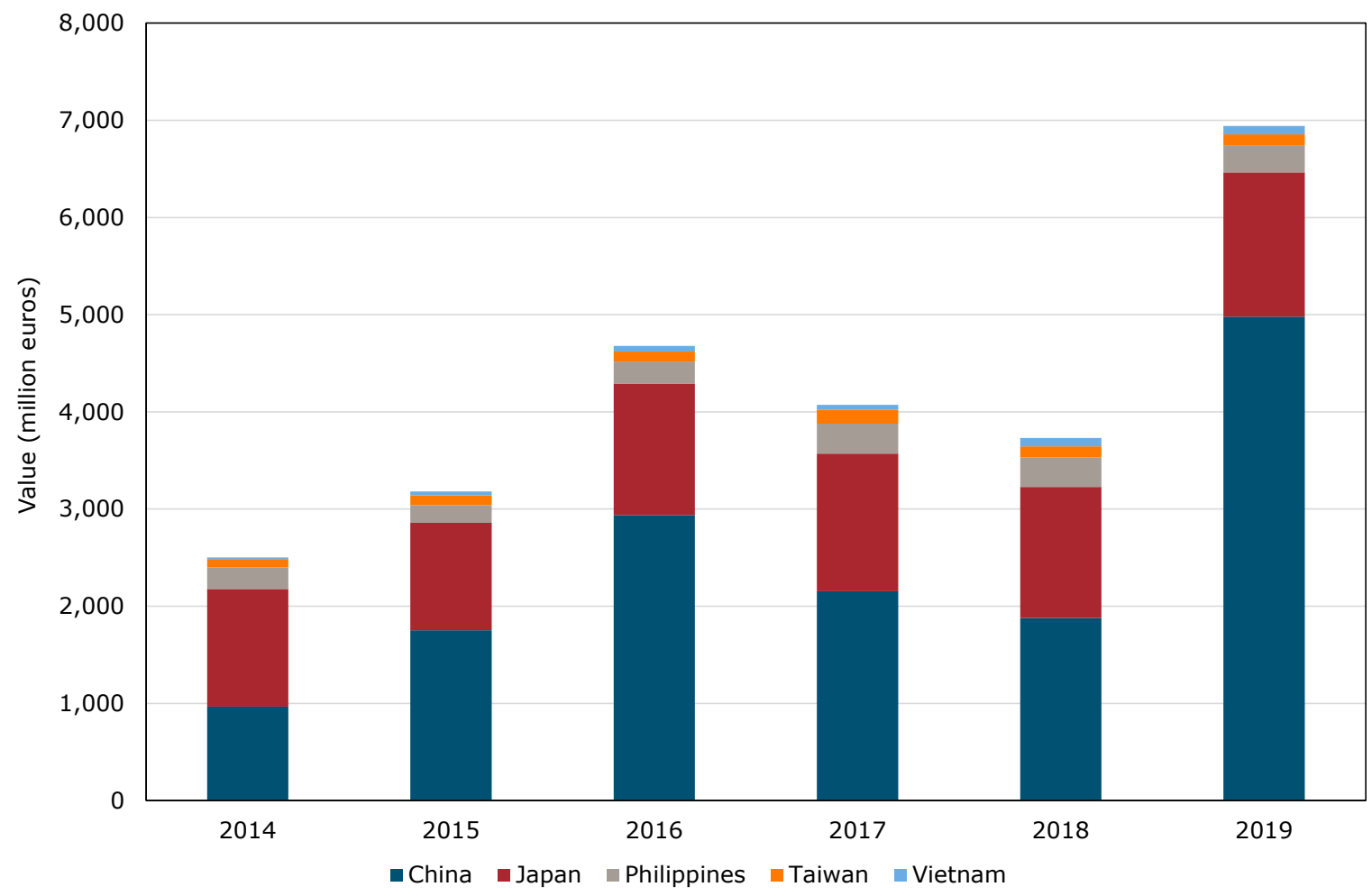

Figure S.1 Export value (million euros) of pig meat products from the EU28 to Asian countries, 2014-2019 


\section{Objective 2: Expand business opportunities by increasing number of clients and the relationships' quality}

An increase in the number of clients could hardly be quantified. Having said so, interviewed Dutch exporters stated an increase in number of new clients from 'zero', 'a few' to 'about ten' per country. All in all, it can be concluded that the companies were rather successful in building new customer relationships, with the most new customers in China, followed by Japan, and Vietnam showing the lowest expansion of business opportunities in terms of number of new clients. In general terms, activities such as setting up exhibition booths were seen as good opportunities to meet both existing customers and strengthen the relationship and meet new prospects. The activities in the campaign contributed to a better understanding of peculiarities of European pig meat: Safe, Residue free, From a controlled production chain, Traceable, Hygienic production circumstances, Sustainable and According to a European standard of animal welfare. Existing customers basically know these qualities already, but their awareness was raised, according to the interviewees. Also new customers and prospects could be reached and explained these qualities, especially in focused activities like network meetings, seminars and study tours. However, some interviewees doubted the effectiveness of network meetings and seminars, as it is a challenge to invite the persons who are most relevant for European exporters.

\section{Objective 3: Creating a higher level of awareness of the different qualities of EU pig meat}

In this study we focus on knowledge and attitudes to analyse whether a higher level of awareness has been realised. The following quality aspects are included in the campaign to communicate: food safety, residue free, controlled production chain, traceability, hygiene, sustainability and animal welfare. Due to limited data an analysis across countries was executed. On average, we find that the campaign activities were appreciated by the stakeholders who participated. When asked, they rated the events very positive. In general terms, results show that almost all respondents indicate to have high to very high levels of awareness for both the groups who did and did not participate in the campaign activities. In addition, stakeholders who had participated in a campaign activity have on average a more positive attitude towards pig meat from Europe compared to those who did not. Also, stakeholders who had participated in promotional activities show more awareness of a few but not all of the quality aspects of EU pig meat. The largest significant average increase can be observed at 'European pig meat is free of residues', followed by 'Trustworthiness of European pig meat' and 'High safety of European pig meat'. The smallest significant average increase is referring to 'Measures are taken to make European pig meat safe.' Also based on interviews it is likely that the campaign has supported export opportunities and awareness rather than caused them. 


\section{Introduction}

\subsection{Objective and scope}

The European pig meat sector is looking for extra market opportunities outside the EU by creating new export market and enhancing existing ones. Referring to this, the Dutch Meat Association (COV) has initiated an EU-funded 'Trusted Pork from Europe' promotion campaign in order to promote European pig meat in five South East Asian countries. They would like to have this campaign evaluated and therefore assigned this study. The objectives of the campaign are directed towards creating economic impact and a higher awareness of the different qualities of pig meat from Europe. This study evaluates the campaign by measuring the degree to which these objectives were met. The Awareness part focuses on evaluating whether a higher level of awareness of the different qualities of EU pig meat is created, whereas the Economic part evaluates whether:

- the position of EU pig meat in the targeted countries is increased as well as the expansion of the sales assortment (i.e. increase in muscles meat);

- the business opportunities are increased by increasing the number of clients as well as the relationships' quality.

The development and execution of the Trusted Pork from Europe promotion campaign is beyond the scope of the study, as is proving the causality between changes in pig meat trade flows referring to the targeted countries and the mentioned promotion campaign. It cannot be measured whether a changing export flow and market relevance is related to the communication campaign, as for instance the period between the promotion activities and the evaluation is too short to expect substantial changes, and the pig meat market is influenced by several factors including outbreaks of animal diseases, border closures and fluctuating currency exchange ratios, which means that it is virtually impossible to distinguish the impact of the promotional campaign from other factors that determine changing market volumes and prices. However, the communication campaign's design is adopted as a starting point. Therefore the countries and quality aspects included in de study are predetermined: China, Philippines, Taiwan, Vietnam, and Japan and seven quality aspects, namely: safety, residue free, controlled production chain, traceability, hygiene, sustainability and animal welfare. The economic part of the evaluation is based on trade flows between the European Union and the targeted Asian countries. As such, five South East Asian countries are included (China, Philippines, Taiwan, Vietnam, and Japan) and the European Union includes the 28 Member States (this means United Kingdom is still included). During the analysis we used data sourced from databases on international trade which were able to provide data for the complete period of the promotional campaign. In this case only Comext ${ }^{1}$ was able to cover the full period of research. Trade flows are expressed in value terms, rather than volumes, although some attention is given to fluctuating prices.

We use the words campaign and promotion campaign interchangeably in this report, whether or not added with the term and title of the Trusted Pork from Europe campaign.

\subsection{Method}

\subsubsection{Promotion campaign}

The Trusted Pork from Europe promotion campaign itself has been developed and executed beyond this study, though it is useful to know what it is about. Therefore we briefly introduce the promotion campaign in this section.

\footnotetext{
1 Eurostat's reference database for detailed statistics on international trade in goods.
} 
The Trusted Pork from Europe promotion campaign has been developed to promote European pig meat in five Asian countries: China, Japan, the Philippines, Taiwan and Vietnam in order to strengthen the market position of European pig meat. The campaign focuses on the quality and safety of European pig meat products and Europe's Farm to Fork approach and the key message is that pig meat from Europe can be trusted because it complies to the highest standards in terms of safety, quality and sustainability. By the integrated quality systems that are implemented throughout the entire production chain, guarantees can be given on quality, traceability of the product and safety of the production process and the products. European standards, norms and rules guarantee and control the production processes concerning pig meat. As such, the promotion campaign is targeted at seven quality aspects concerning European pig meat ${ }^{2}$

- Safety

- Residue free

- Controlled production chain (in general and i.e. concerning forbidden substances)

- Traceability

- Hygiene measures

- Sustainability

- Animal welfare

The promotion campaign lasted three years (April 2017 - March 2020). During that period a diverse range of promotion activities were organised through which information on the different qualities of EU pig meat was communicated to stakeholders: trade fairs (also including seminars, product tasting and chef contests), study visits, a website, billboards. All activities were planned to be carried out in cohesion to reinforce each other.

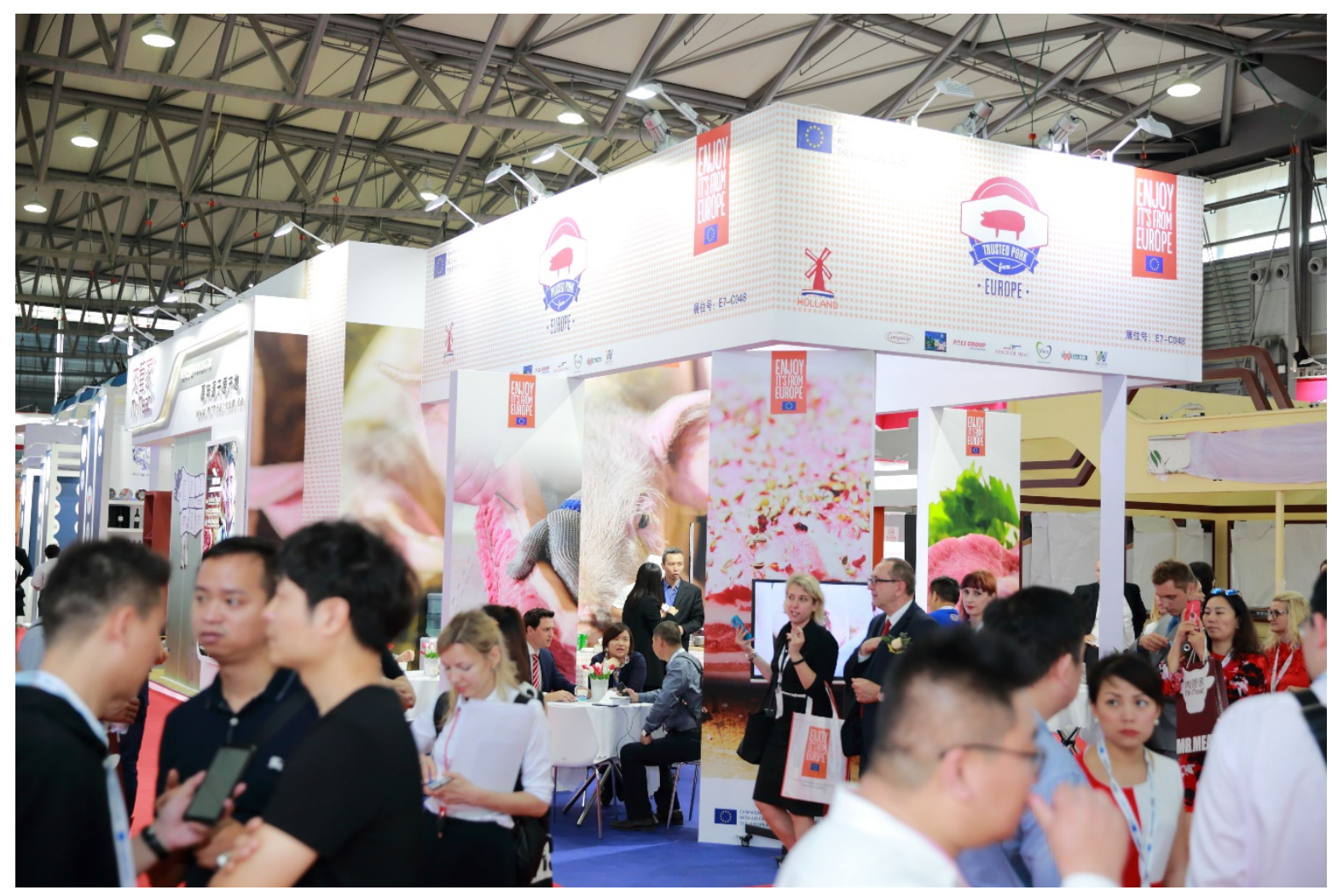

Figure 1.1 Promotion campaign "Trusted Pork from Europe" (Source: COV)

\footnotetext{
2 We have adopted the aspects, we did not research them.
} 


\subsubsection{Economic development}

To carry out the economic part of the evaluation, we used an approach based on quantitative and qualitative data, trade data and interviews respectively. As the world market for pig meat has been firmly shaken up, due to large-scale and widespread outbreaks of African Swine Fever, we are also describing the context of the world trade of pig meat briefly, as this is influencing export volumes to Asian countries also.

On the one hand we used trade data for researching whether the position of EU pig meat in the targeted countries is increased and whether the expansion of the sales assortment has increased during the course of the communication campaign. We used data from Comext, which is Eurostat's reference database for statistics on international trade in goods. The used product codes are provided in Appendix 1. In general, we aimed at gathering data for a longer period than the promotion campaign ran. This enabled us to better compare export values before and after the promotion campaign. For example, 2016, the year just before the campaign started, showed some peculiar trade effects in China. Therefore, we started the time range in 2014 and compared sales values in 2019 and 2014; data for 2020 were not (sufficiently) available to take into account.

In addition to this, we also held seven in-depth interviews with stakeholders, who are familiar with the activities of the Trusted Pork from Europe promotion campaign. The interviews were held by phone according to protocol with stakeholders. The stakeholders are representatives from (Dutch) companies who are commercially based in one or more EU countries. The structured interviews took half an hour to one hour and consisted of open-ended questions. The interview started with getting clear in which of the targeted countries one is commercially active and was generally aimed at getting insight into the development of the number and the quality of relationships with (new and existing) business client, as well experiences with the promotion campaign and corresponding activities. Also changes in the sales assortment were discussed. The interview ended with some time left for the interviewee to make some comments if desired.

\subsubsection{Level of awareness}

The second part of the evaluation is aimed at analysing whether a higher awareness of the different qualities of EU pig meat has been realised. Awareness of these qualities can be seen as a necessary first step towards purchasing a product. The Hierarchy of Effects Model (Lavidge \& Steiner, 1961) describes the multiple steps towards purchase: awareness (knowledge), liking/preference (attitudes), conviction and purchase. In the study we focus on the first two steps: knowledge and attitudes. Specifically, the focus lies on knowledge about the quality aspects of EU pig meat (safety, residue free, controlled production chain, traceability, hygiene, sustainability and animal welfare) and attitudes towards EU pig meat. We use a wider scope of awareness for this study than the Hierarchy of Effects Model, by taking attitudes into account in addition to knowledge, so that we can determine to what extent the Trusted Pork from Europe promotion campaign as a whole not only leads to more awareness of the quality aspects of EU pig meat, but also leads to a more positive attitude towards EU pig meat.

We measured whether the campaign as a whole contributes to a higher awareness and carried out a t-test to check whether a higher level of awareness was observable among stakeholders who had participated in a promotional activity that was part of the campaign, relative to stakeholders who had not (yet) participated in such an activity. The expectation is that awareness of EU pig meat quality aspects is higher among stakeholders who have taken part in a campaign activity, compared to stakeholders who did not take part (yet) in such an activity. To this end, a quasi-experimental design is used and a survey was developed. This design is appropriate since there is no random allocation of stakeholders to either the experimental group or the control group (fair visitors choose for themselves if they participate in a certain activity and we are not going to interfere in this choice) and respondents only complete a survey once. With this set-up we aimed at a high response rate and meeting the requirements of a high level of practicability and feasibility. 
People attending an promotional activity were approached by a hostess and requested to fill out a questionnaire. The participants are first asked whether they have already completed this survey on EU pig meat qualities before. Only when those people have not yet completed the survey before, they were subsequently asked to complete the survey. Fair visitors that participated in one of the activities (trade fairs, seminars, product tasting and chef contest) are part of the experimental group. At the same time, the fair will deliver respondents for the control group. The control group consists of fair visitors who have not (yet) participated in the respective activity/activities. Fair visitors are approached by a host/hostess on a location of the fair where none of the activities are held or on entering the fair ground, to conduct the same survey.

A structured survey was developed aimed at measuring the effects of the campaign and while at the same time keeping the survey as short as possible. For all the target countries these surveys consisted of closed-ended questions measuring respondents' awareness of the different quality aspects concerning EU pig meat and attitudes towards EU pig meat. Knowledge and attitudes thus are the two key components in the survey, in addition to pig meat quality aspects. To ensure that participants would complete the entire survey, the survey started with relatively easy questions about the social demographics: age, gender and occupation were included. Thereafter two blocks of questions followed which are the evaluations core referring to attitude, pig meat qualities and supplemented with key elements of the promotion campaign. A validated scale was used to measure attitude ${ }^{3}$ (Ajzen, 1991; Onwezen et al., 2013). COV provided the information promotion campaign and based upon this seven pig meat quality aspects are included in the survey. ${ }^{4}$ These aspects were operationalised into 12 items, e.g. 'On average, I now know that European pig meat is free of residues' or 'On average, I now know that pig meat from Europe complies to the highest international standards in terms of sustainability'. In addition to this, it provided the four items referring to the key message: safety, quality, sustainability and animal friendliness (welfare) of EU pig meat. Since context is relevant, we were also interested in the circumstances in which the survey was completed and assessed this by the question: 'Overall, how would you rate the event(s) that you attended today?' (poor to excellent). Finally, two questions were added in order to make sure effects could be measured as meant and minimise clouding: 'Have you heard of the Trusted Pork from Europe campaign?' (yes, no, or do not know) and 'Have you previously attended an event regarding the Trusted Pork from Europe campaign before, in the last three years?' (yes or no). By doing this, we do not only prevent for confusion, but simultaneously strengthen the validity of the study, as these data contribute to increasing the probability that any (statistical) effects that are found can indeed be attributed to the promotion campaign. Except for socio-demographic questions, all questions could be answered using 5-point Likert scales. To ensure the quality of translation, we used a forward and backward translation of the questionnaire in the different, local languages.

The data were analysed statistically using the program SPSS. Since it was agreed the data analysis should be conducted separately for each of the participating countries we follow this approach. Independent samples t-tests are used in order to statistically test whether the level of awareness of a certain quality of EU pig meat is statistically different in a control group, compared to the experimental group. In the end, however, it turned out that fewer data were collected than planned. Particularly the recruitment of respondents targeted for the control group resulted in very low numbers of respondents. A post hoc power analysis showed an inadequate statistical power. This means that the power found is below the threshold value $(<80 \%)$ and therefore the t-test analysis cannot be performed. Consequently, descriptive analysis is executed for each of the participating countries. However, we found that across all countries combined a post hoc power analysis showed adequate statistical power. As such, across all countries combined we will evaluate whether a higher awareness the different qualities of EU pig meat has been created.

\footnotetext{
3 An individuals' response with respect to a given object, idea or situation.

4 Safety, free of residues, controlled production chain, traceability, hygiene, sustainable production and animal welfare standards.
} 


\section{Results: Economic Impact}

\section{$2.1 \quad$ Miscellaneous developments}

This chapter begins with some background information and briefly describes three recent developments influencing the world trade of pig meat.

The first one concerns China, which is in terms of pig production and consumption by far the largest country among the five focus countries in the promotion campaign. Pig production in China fluctuated considerably in the past couple of years. Around 2016 stricter governmental regulations on environmental protection led to many (backyard) farmers stopping production. Reduction in the domestic supply of pig meat led to increasing prices for pigs and pig meat, as well as import flows of pig meat from all over the world. Pig meat is a very important product for Chinese consumers, and part of their culture. High consumer prices could easily lead to societal dissatisfaction. The Chinese government has therefore opened strategic reserves, as well as increasingly licensed abattoirs worldwide to export to China, which made additional import volumes possible.

Another factor playing a role in the trade of pig meat is the trade war between the USA and China, where disadvantages for US exporters turned out to become advantages for EU exporters. A relative cost disadvantage in the EU compared to the US (Hoste, 2020) was compensated by favourable import fees and currency ratios compared to those for the US, in the trade with China.

Finally, a major factor arising in 2019 is the massive outbreak of African Swine Fever, resulting in a loss of pig numbers in many East Asian countries, including China, Vietnam, Philippines and Taiwan, but not in Japan. China alone lost some $50 \%$ of the pig numbers, propelling import demand substantially. Still the total world trade of pig meat, some 7 or 8 million tonnes annually, would not be sufficient to fill the emerged demand gap. Pig prices increased steeply, to unprecedented levels. At the end of 2019 the import flow from the EU28 alone peaked to almost 900 million euros in November 2019, in the run-up to the Chinese New Year (end of January).

\section{$2.2 \quad$ Trade flows}

This section describes the developments in trade flows, starting with the development of the pig meat export from EU to the five South East Asian countries. From Figure 2.1 and Figure 2.2 it is shown that the total export value of pig meat (all products) has increased since 2014. Major destination is China, followed by Japan. China is showing a strong fluctuation and overall increase. Before the Trusted Pork from Europe promotion campaign started, the total export value was increasing already, but in the years 2017 and 2018 the total export value has reduced. 2019 shows a very strong increase of the total export value to about $€ 7 \mathrm{bn}$.

Major exporters within the EU are Spain, Germany and Denmark, followed by the Netherlands and France, with a joint $89 \%$ market share of the total EU28 export to these focus countries. Compared to 2014 the total value roughly quadrupled from Spain, the Netherlands and Germany. 


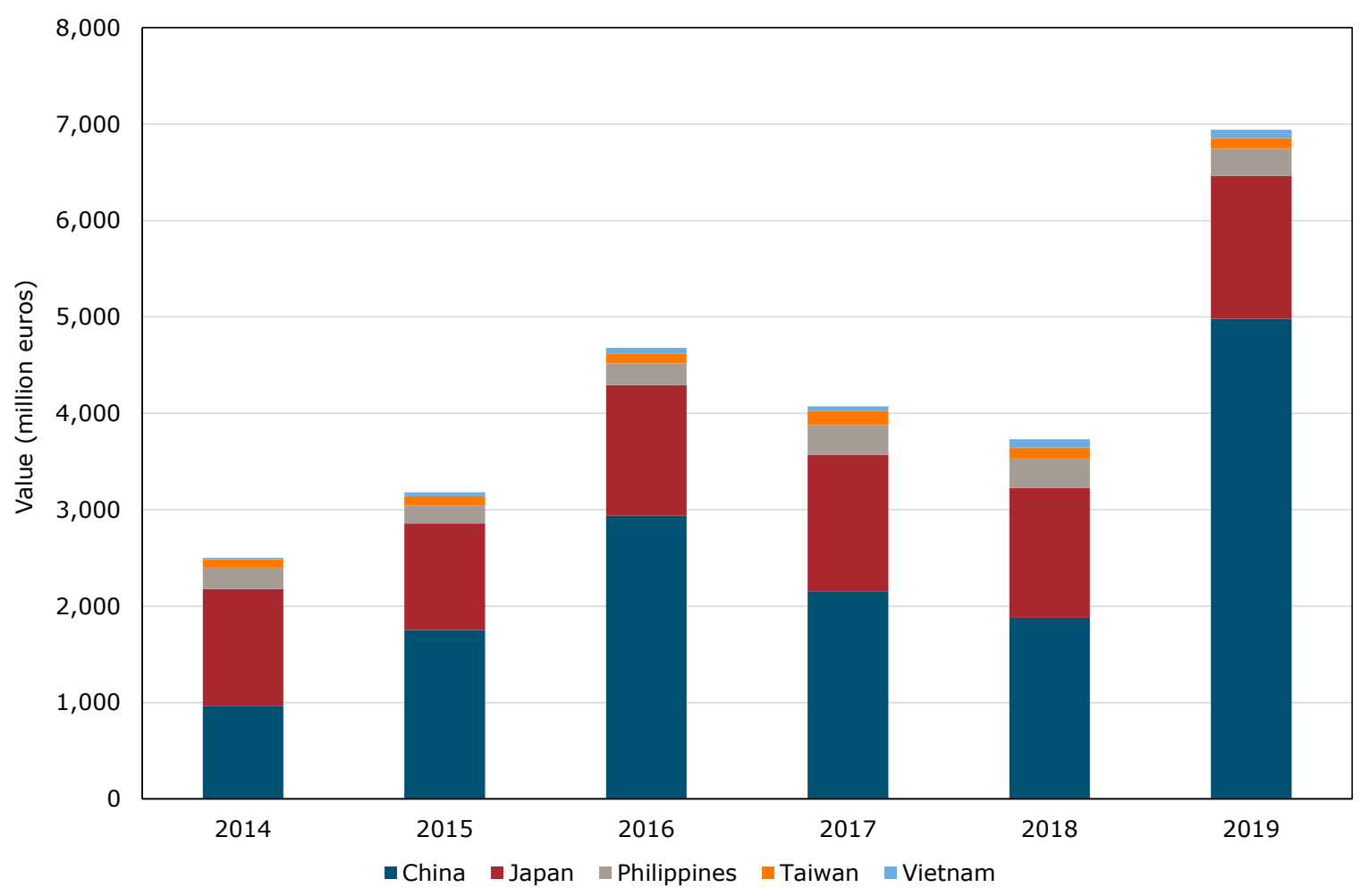

Figure 2.1 Export value (million euros) of pig meat products from the EU28 to Asian countries, 2014-2019

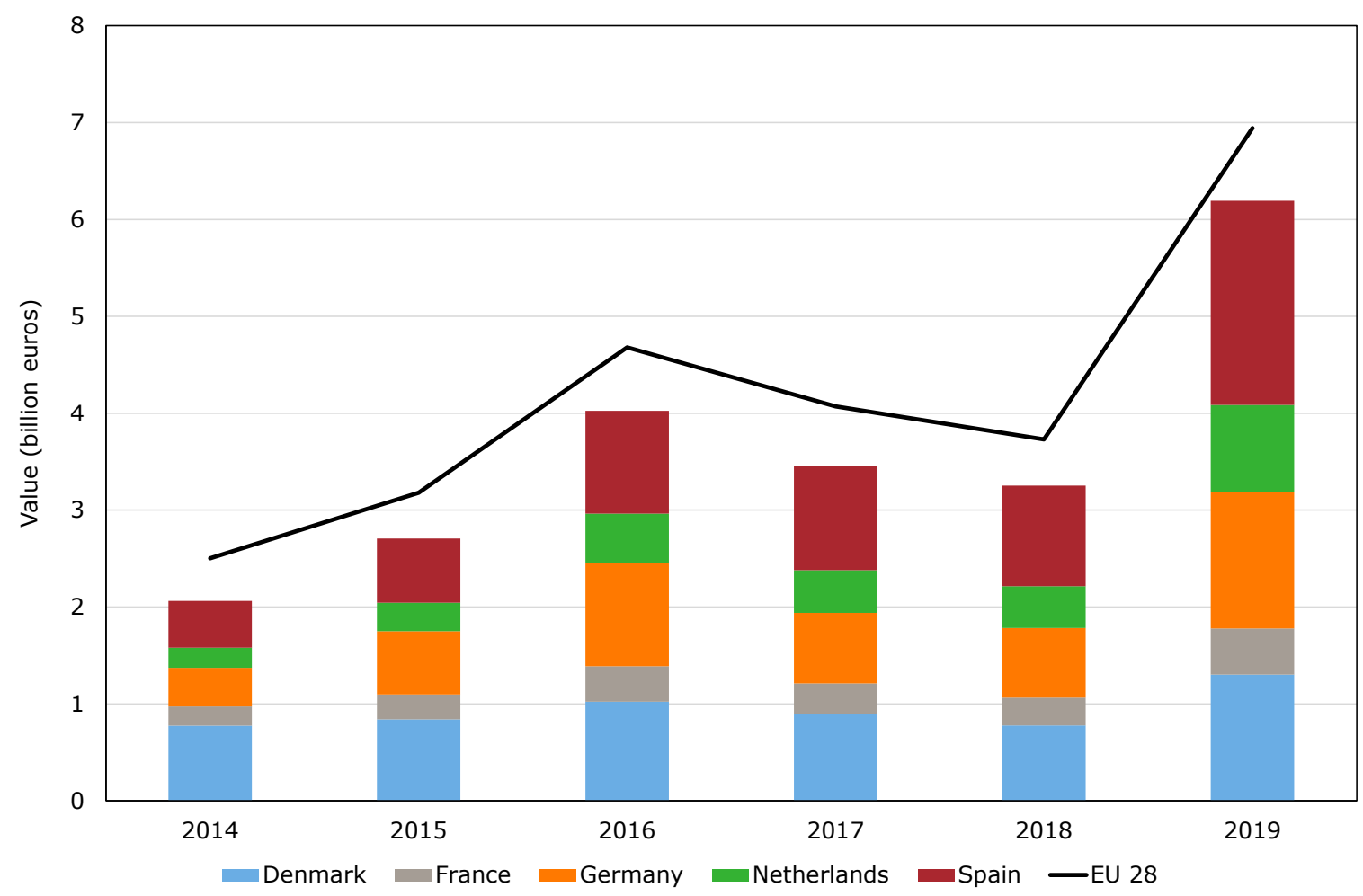

Figure 2.2 Export value (million euros) of pig meat products to China, Japan, Philippines, Taiwan and Vietnam (total), from largest EU countries and EU28 as a whole

Figures 2.3 to 2.7 show that the export to China quintupled between 2014 and 2019 , from $€ 966 \mathrm{~m}$ to $€ 4.98 \mathrm{bn}$, with the relatively largest increase in lard and fat. However, in absolute value, frozen products were far more important, and eight times higher in 2019 than in 2014. In volume terms the 
total export to China was 3 times higher in 2019 than in 2014, showing that the increased export value comes both from volumes and a price effect.

Japan, with a total export value from the EU28 amounting to $€ 1.5$ bn in 2019, shows a very modest increase over time of some $20 \%$ of total sales value, half of it due to higher prices. Frozen products are by far $(93 \%)$ the most important category in export to Japan.

The total sales value of pig meat products to the Philippines amounted to some $€ 280 \mathrm{~m}$, of which frozen and offal were the typical product categories. Between 2014 and 2019 the sales value increased about $30 \%$, mainly due to higher prices.

Taiwan's import peaked in 2017 ( $€ 145 \mathrm{~m})$, but 2019 resulted in about $€ 110 \mathrm{~m}$, with the focus on frozen products. The total import volume in 2019 was some $8 \%$ lower than in 2014, but due to higher prices 2019 still showed about $30 \%$ higher sales value: frozen products' volumes increased, but for offal it decreased.

The smallest country of the five Asian destinations, in terms of import value of pig meat products from the EU28 is Vietnam, with a total import value of $€ 86 \mathrm{~m}$ in 2019 , five times higher however, than in 2014. Offal (58\%) and frozen products (31\%) are the most important product categories.

Relatively, Vietnam and China saw the largest increase of import value between 2014 and 2019.

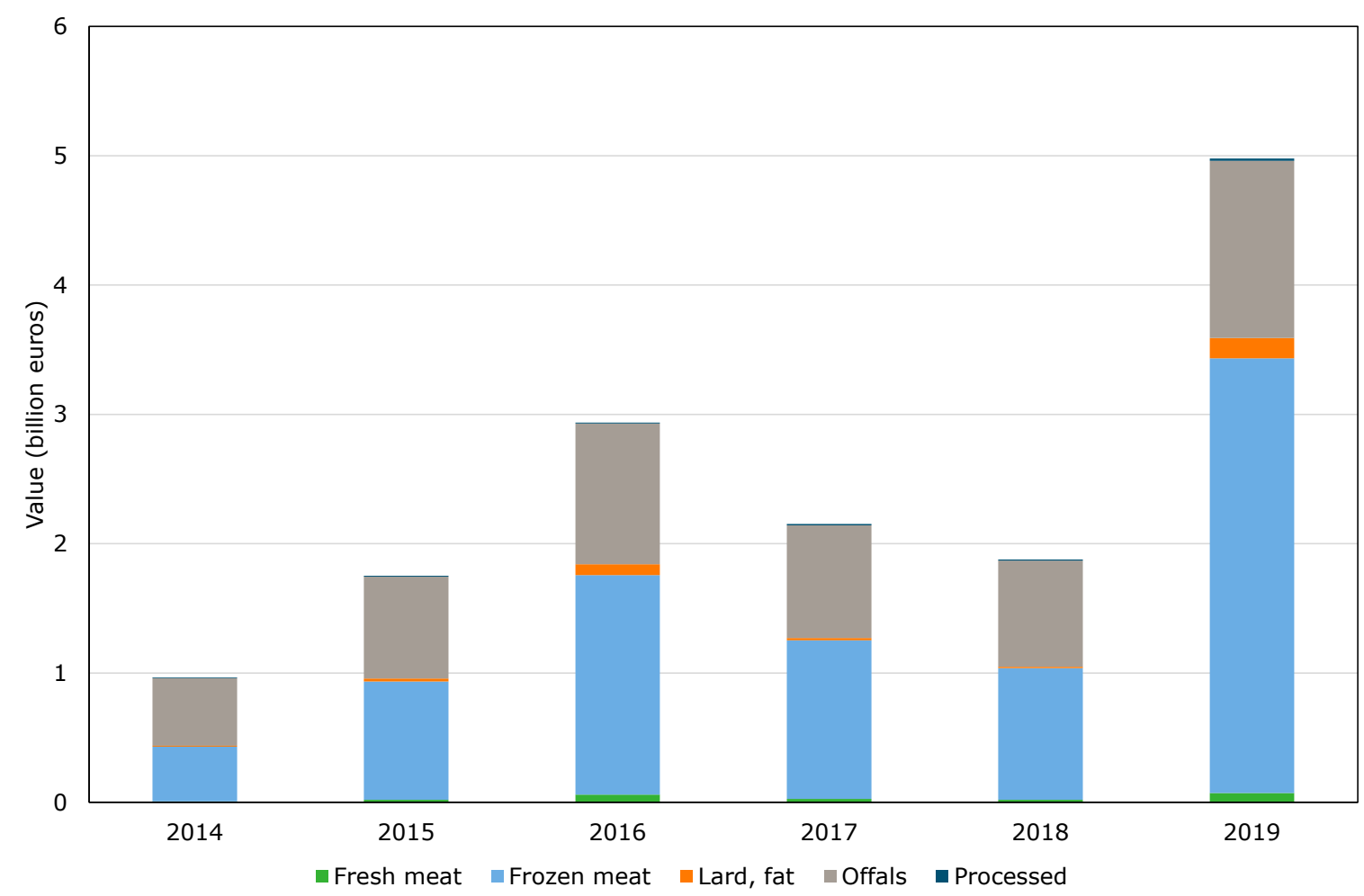

Figure 2.3 Export value of pig meat products from EU28 to China, 2014-2019, split into product categories 


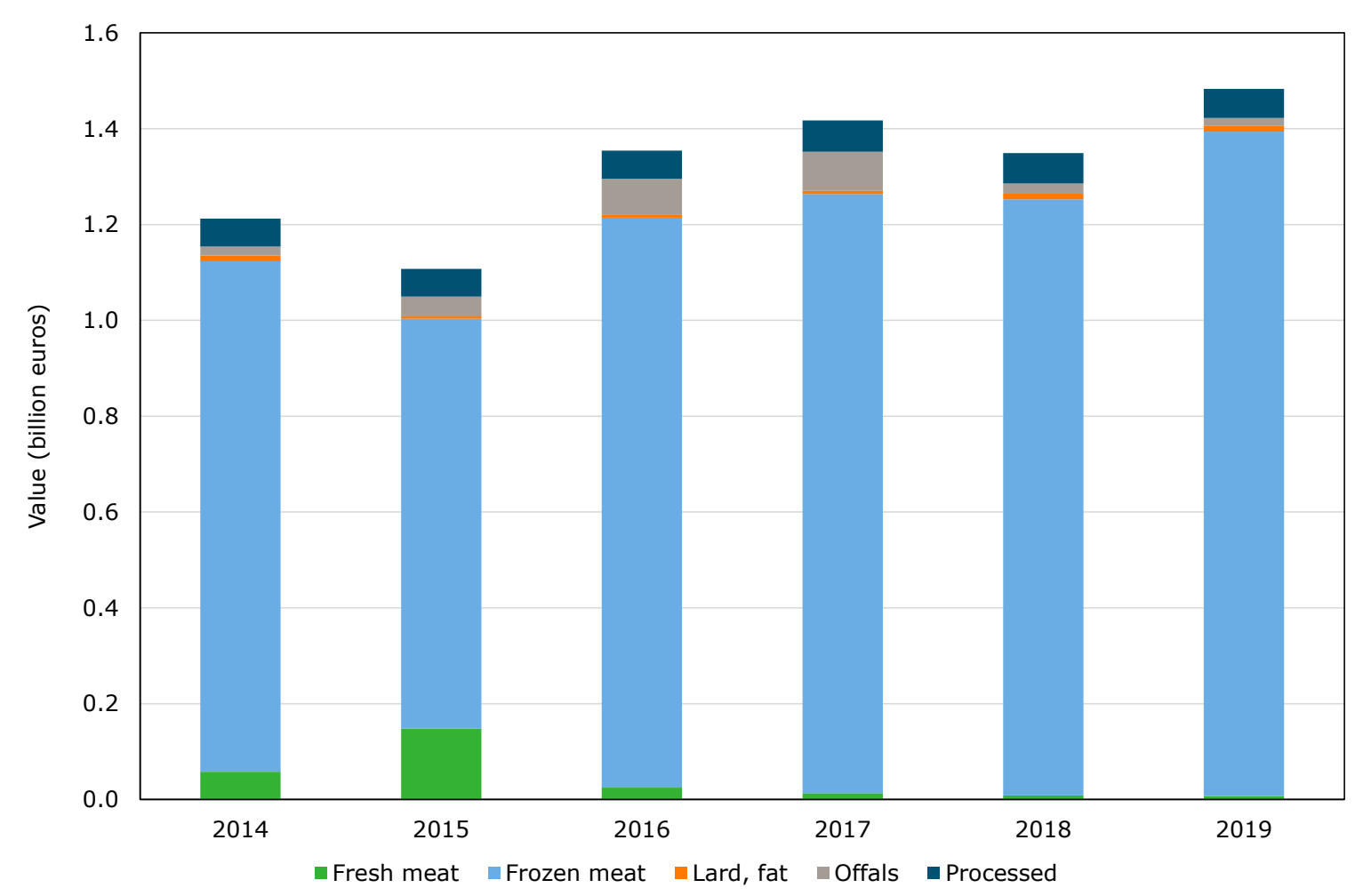

Figure 2.4 Export value of pig meat products from EU28 to Japan, 2014-2019, split into product categories

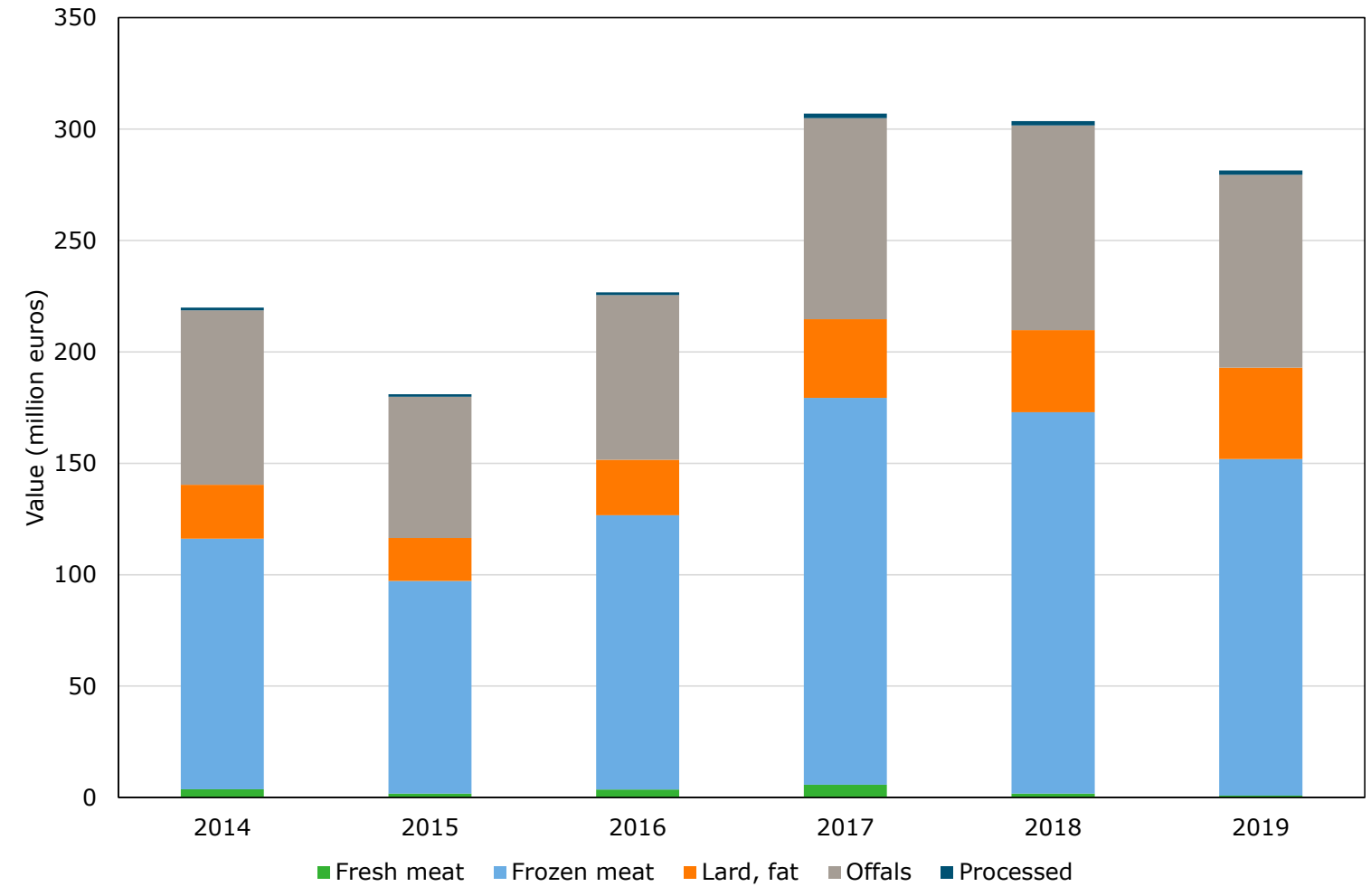

Figure 2.5 Export value of pig meat products from EU28 to Philippines, 2014-2019, split into product categories 


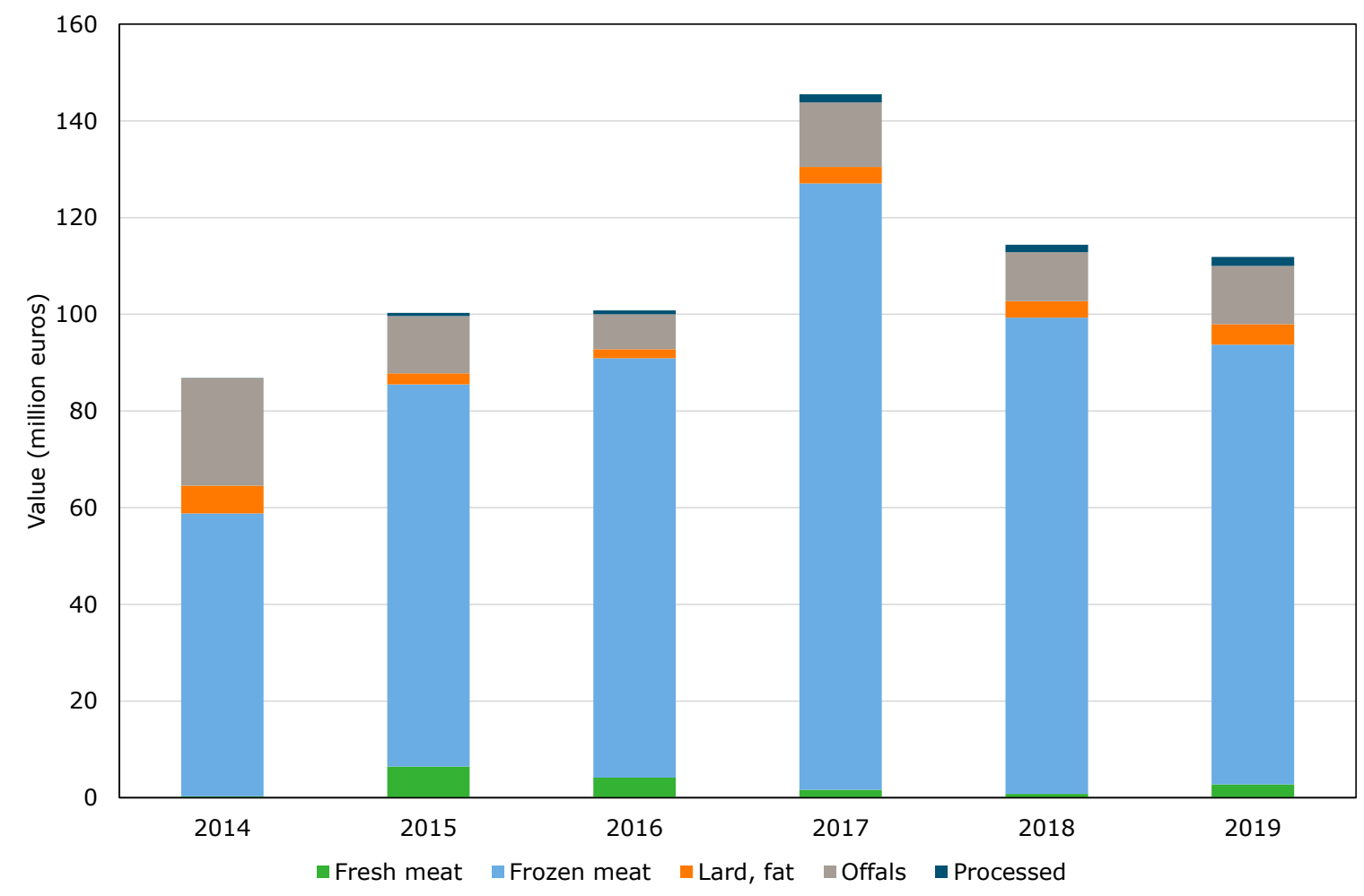

Figure 2.6 Export value of pig meat products from EU28 to Taiwan, 2014-2019, split into product categories

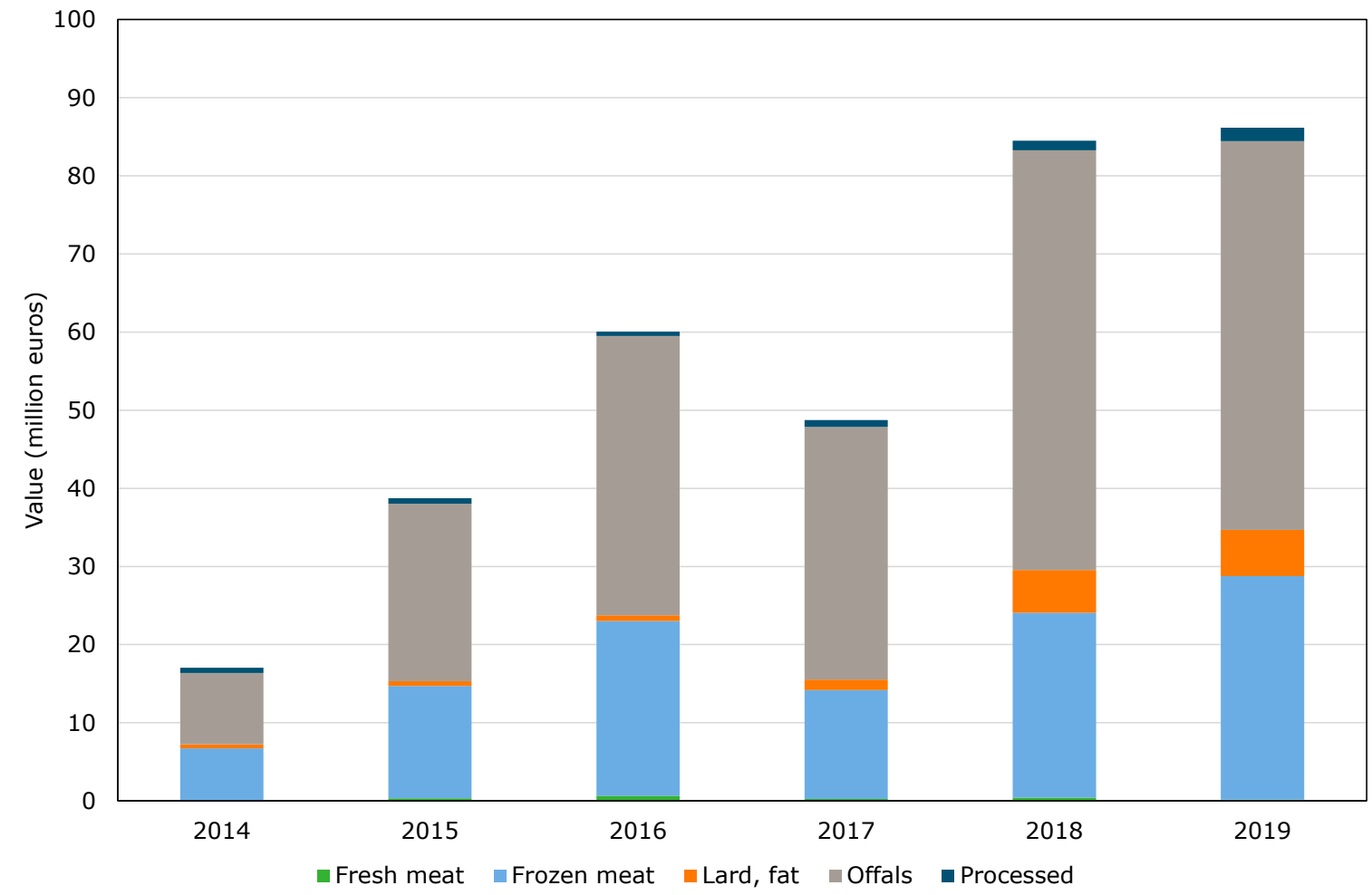

Figure 2.7 Export value of pig meat products from EU28 to Vietnam, 2014-2019, split into product categories

Figure 2.8 shows the increasing relevance of the focus countries in the total EU28 pig meat export value. For frozen meat the five destination countries took 55\% of the total EU28 export value in 2019, up from about $32 \%$ in 2014. For lard and fat this increased from 9 to $29 \%$, and for offal from 36 to $70 \%$. Overall it can be concluded that between 2014 and 2019, the focus countries have gained 
relevance for EU exporters, especially for frozen meat and offal. For lard and fat the relative increase is evident as well, but in terms of total export value this product category is less important. For each of these three product categories, China is the largest, both in market share and increase of market share in total export value from the EU.

The market share of the five destination countries in the total EU export value of fresh meat and processed meat is very limited, about $1 \%$ in both product categories.

For all product categories together, the market share of the five Asian destination countries in the total EU pig meat export value increased from $11 \%$ in 2014 to $24 \%$ in 2019 . Also in volume terms the joint market share of the five countries in the EU pig meat export increased, from $13 \%$ in 2014 to $26 \%$ in 2019. So the market relevance of these five countries for EU exporters has doubled over this period.

One of the economic objectives of the promotion campaign was to increase the position of EU pig meat in the targeted countries. From the analysis it can be concluded that the market relevance of the five Asian destination countries has doubled over the period 2014-2019, in terms of total export value from the EU28. We cannot judge whether this is caused by the Trusted Pork from Europe promotion campaign, given the many other factors strongly influencing the world trade of pig meat, especially in the year 2019 (see Section 2.1).

Another economic objective was an expansion of the sales assortment, especially focusing on sales of higher priced products, rather than edible offal. This topic was approached by trade data, but also in the interviews (see Section 2.3). From the trade data it can be seen that some shift has taken place towards sales of muscle meat (frozen and fresh meat), rather than lard, fat and offal. The sales value of the latter group, representing lower value products, classically exported to Asian destinations, was multiplied 2.5 times in 2019 compared to 2014. Sales of muscle meat (frozen and fresh) in 2019 amounted to 2.9 times the value in 2014. In volume terms the lower value products increased 1.8 times, but the muscle meat 2.7 times in 2019 compared to 2014. It is concluded that the increased export resulted in an higher share of muscle meat (frozen and fresh) than of lower value products (lard, fat and offal), both in volume and value percentage. Similar to the former conclusion we want to state that we cannot judge whether this is caused by the Trusted Pork from Europe promotion campaign or not, given the many other factors strongly influencing the world trade of pig meat, especially in the year 2019.

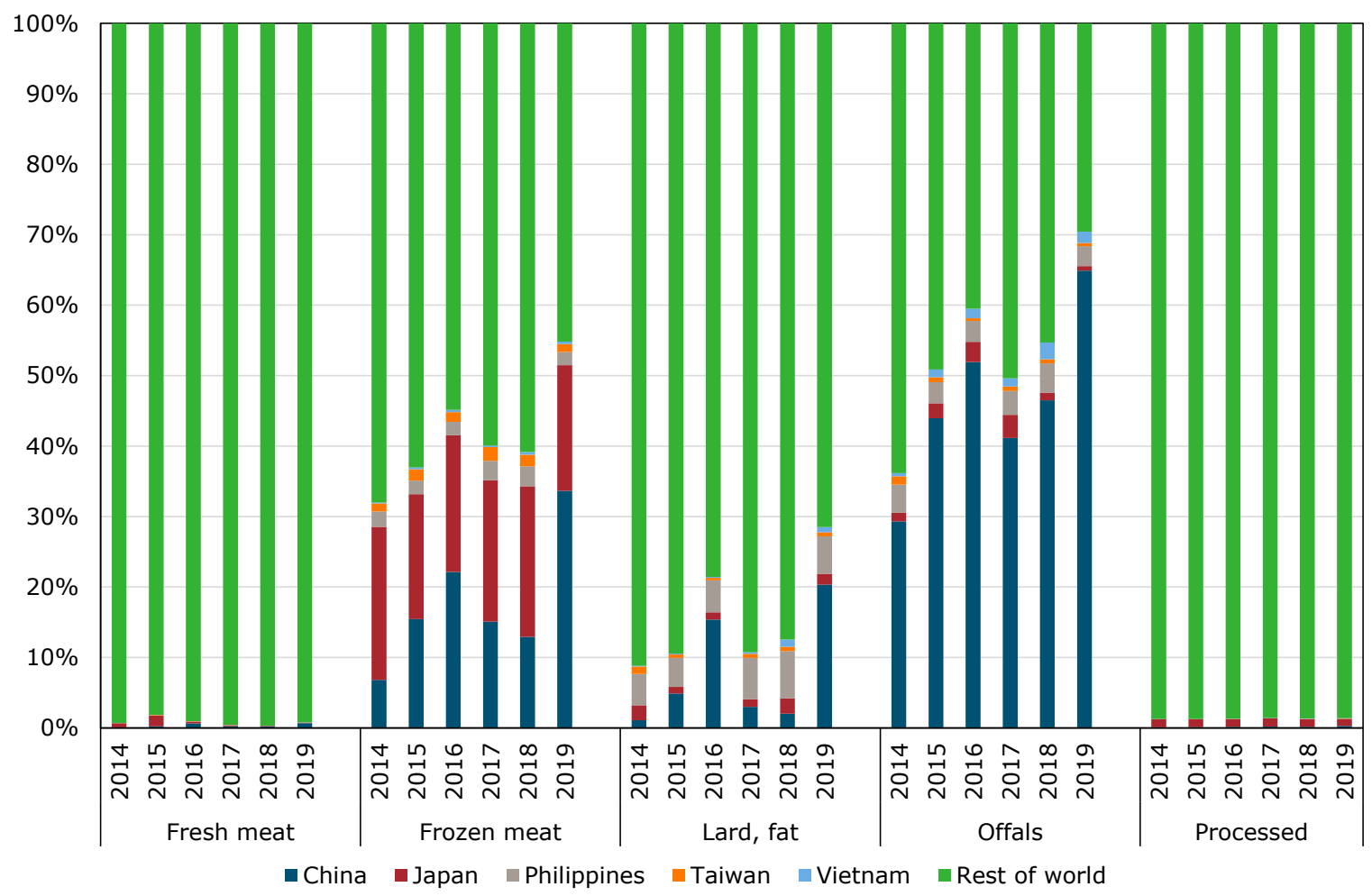

Figure 2.8 Market share of Asian countries (and Rest of the World) in total European export value of pig meat, per product category 


\subsection{Business opportunities}

In addition to the trade flow figures seven interviews with stakeholders were held. These were aimed at exploring the business opportunities in terms of number of clients of the quality of relationships with business. Also changes in the sales assortment were discussed. The stakeholders were Dutch exporters, who were familiar with the activities of the Trusted Pork from Europe promotion campaign.

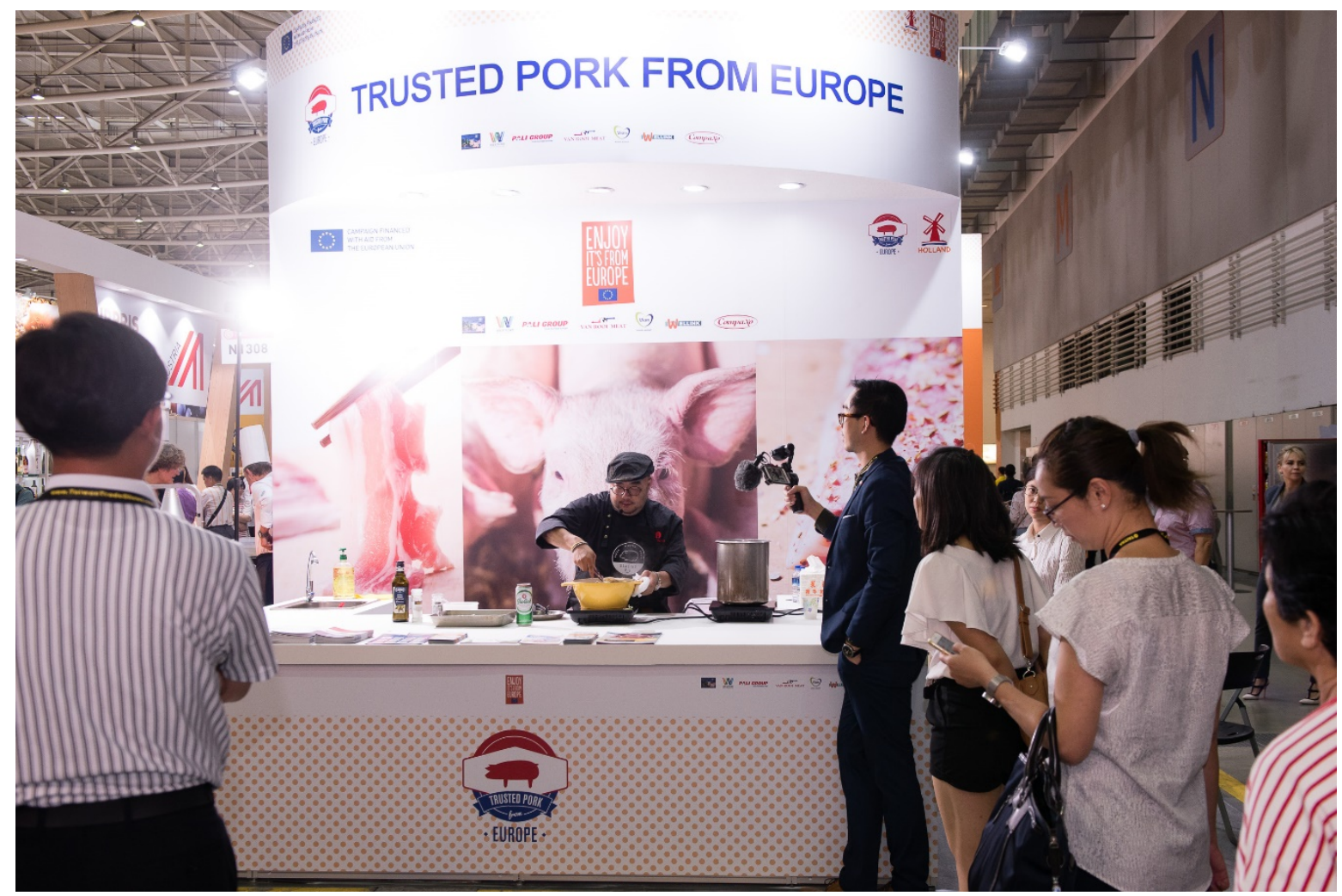

Figure 2.9 Communication campaign "Trusted Pork from Europe" (Source: COV)

Based on these interviews an increase in number of clients could not simply be quantified, for several reasons. Sometimes interviewees refused to be as explicit in exact numbers as asked; sometimes they hesitated to mention numbers as it was not clear for them whether changes in client numbers were related to the promotion campaign. Furthermore, it appeared to be a matter of definition, given typical trade patterns: trade sometimes takes place directly to customers like processors or restaurants, but sometimes clients are importers, who in turn sell to their clients.

Having said so, most interviewees stated an increase in number in new clients per country. The number of new clients per company interviewed varied from zero to tens of clients in China. In Taiwan and the Philippines there were 'a few' new clients on average, and trade is preferentially done via middlemen/importers. In Vietnam hardly a new client was contracted, and in Japan the number of new clients differed: zero, 'a few', to 'about ten'. All in all it can be concluded that the companies were quite successful in building new customer relationships, with the most new customers in China, followed by Japan, and Vietnam showing the lowest expansion of business opportunities in terms of number of new clients.

According to the interviewees there is some shift in the sales assortment. Increasingly muscle products (category frozen) are being sold, but also offal are well in demand. Especially China demands primal cuts, and also stomachs. In Japan there is more sales to food service. Japan has a specific custom system, with a threshold price level; cheaper products can only be imported by combining with other, more expensive, products. This results in typical sales via traders, rather than direct to e.g. processors. 
We asked the interviewees about their perceptions on sales opportunities in the destination countries. In the short term these markets are very attractive. However, recovery of African Swine Fever is expected in a few years, and market opportunities in China are expected to become seriously reduced. The Philippines and Vietnam are then seen as alternative sales market. Still, unique selling points will become even more relevant in the near future. Trust, the lead term of the promotion campaign, is then a prerequisite. In that perspective this term was perceived a good choice by the majority of the interviewees, although one respondent suggested that using this term would rather lead to doubting the actual trustworthiness of European pig meat.

Another goal of the promotion campaign was to improve the quality of relationships with business clients. In general terms, the activities like a booth on several exhibitions, were seen as good opportunities to meet both existing customers and strengthen the relationship and meet new prospects.

The activities in the campaign contributed to a better understanding of peculiarities of European pig meat: Safe, Residue free, from a controlled production chain, traceable, Hygienic production circumstances, Sustainable and according to a European standard of animal welfare. Existing customers basically know these qualities already, but their awareness was raised, according to the interviewees. Plus new customers and prospects could be reached and explained these qualities, especially in focussed activities like network meetings, seminars and study tours. However, some interviewees doubted the effectiveness of network meetings and seminars, as it is a challenge to invite the persons who are most relevant for European exporters.

It can be concluded that interviewees were happy with most of the activities, as it gave a good opportunity to show the product qualities and supply chain approach of European pig meat, and the campaign led to strengthened relationships with existing clients and formed a good basis for acquiring new clients. Given the market expectations for the next years, strengthening the market potential is essential for continuation of pig meat export to east Asian countries. 


\section{Results: Level of awareness}

\subsection{Sample}

A survey was carried out in order to evaluate whether a higher awareness of the different qualities of EU pig meat has been created. In total a sample of 691 surveys was collected in China, Japan, Philippines and Vietnam. The data are checked for completion, standard deviation and assignment to activities and consequently 569 surveys remained for analysis, representing three countries China $(68 \%)$, Philippines (23\%) and Vietnam (9\%). Table 3.1 gives the sample sizes per country.

Table 3.1 Sample size, per country and in total (in numbers and percentage)

\begin{tabular}{lccc} 
Country & Frequency & Percent & 68 \\
China & 386 & 23 \\
\hline Philippines & 130 & 9 & 9 \\
\hline Vietnam & 53 & 100 \\
\hline Total & 569 & 100 \\
\hline
\end{tabular}

Since we are interested in the difference in the level of awareness between stakeholders who have taken part in a campaign activity, compared to those who did not take part (yet) in such an activity, stakeholders are assigned to two groups: the control and campaign (experimental) group.

A question was included in the survey in order to prevent confusion and more accurately attribute any effects found to the Trusted Pork from Europe campaign itself, which resulted in extra dropouts (minus 295). As such, to the campaign group belong those respondents who have participated in one of the respective campaign activities and answered positively to the question whether they have heard of the Trusted Pork from Europe campaign. Respondents who have not (yet) participated in one of the respective campaign activities and have not heard of the campaign or do not know, are assigned to the control group. Consequently, any effects that are found can with more certainty be attributed to the promotion campaign. Most respondents belong to the experimental group $(79 \%, \mathrm{n}=217)$ and fewer respondents belong to the control group $(21 \%, n=57)$, Table 3.2 .

Table 3.2 Distribution of respondents, total and per country (in numbers)

\begin{tabular}{lcccc} 
Country & Control & Campaign & Total & 274 \\
Total & 57 & 217 & & \\
\hline Per country: & & 174 & 193 \\
\hline China & 19 & 19 & 57 & 24 \\
\hline Philippines & 38 & 24 & 24 \\
\hline Vietnam & 0 & & \\
\hline
\end{tabular}

A consequence of the resulting dropouts is that for statistical comparisons the number of respondents per group is of insufficient statistical power to perform statistical tests per country. ${ }^{5}$ However, statistical analyses are still possible at the total level, across all countries. ${ }^{6}$ Since it was agreed the data analysis should be conducted separately for each of the participating countries we follow this approach in the sections below and present results per country. Japan and Taiwan, though, are not included because in these countries no or inadequate surveys were held. However, due to statistical

5 (power< 0.80; post-hoc poweranalyse (GPower)).

6 (power $>0.80$; post-hoc poweranalyse (GPower)). 
power we are able to start with an exception and evaluate whether across all countries combined a higher awareness of the different qualities of EU pig meat has been created.

\subsection{Promotion campaign}

The Trusted Pork from Europe promotion campaign reached out in several South Asian countries informing about the quality aspects of pig meat from Europe. Since we are interested in the difference in the level of awareness between stakeholders who have taken part in a campaign activity, compared to those who did not take part in such an activity, stakeholders are assigned to two groups: the control and campaign (experimental) group. Specifically, the expectation is that the attitude towards and knowledge about the quality aspects of pig meat from Europe is higher among stakeholders who have taken part in a campaign activity, compared to stakeholders who did not take part (yet) in such an activity.

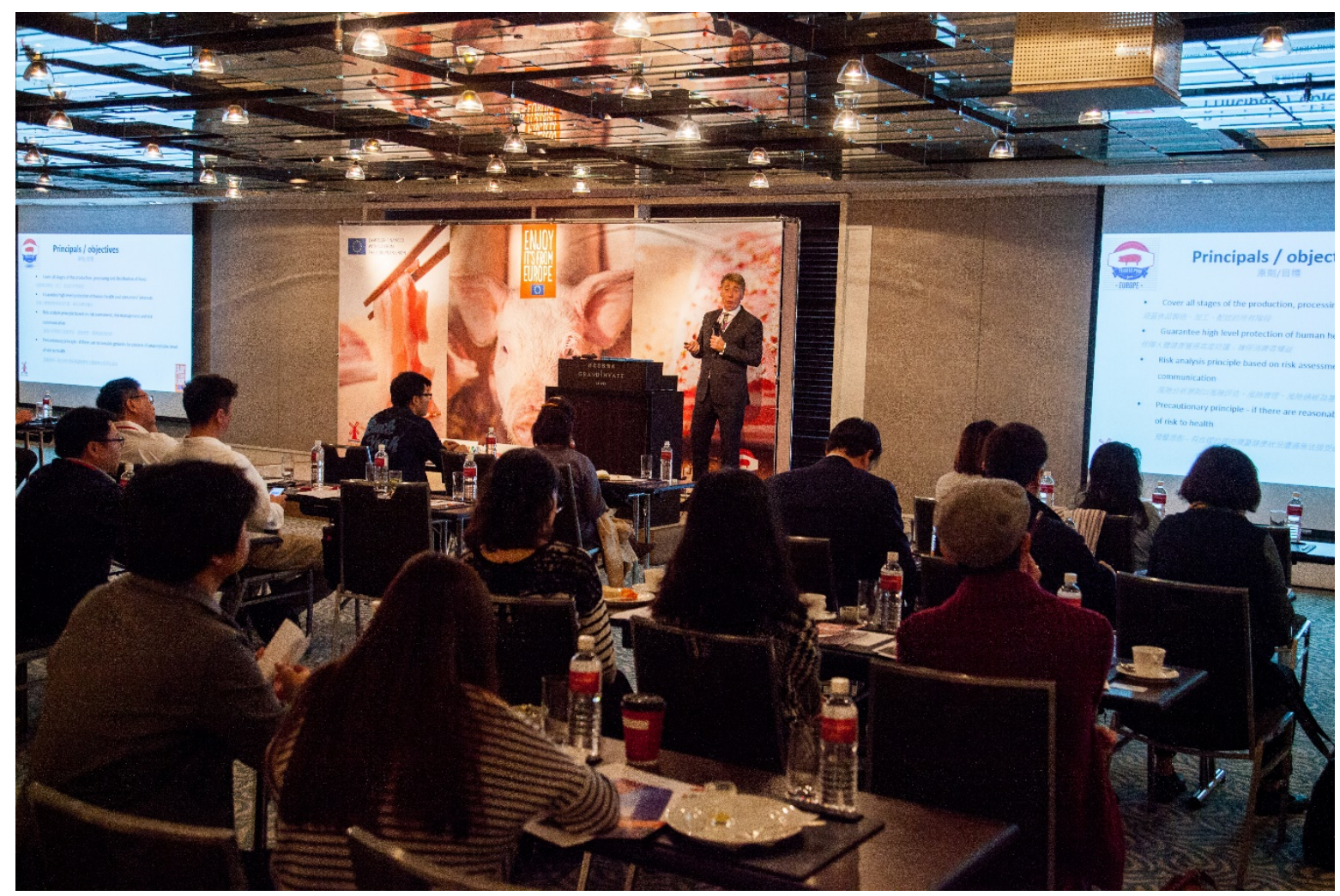

Figure 3.1 Communication campaign "Trusted Pork from Europe" (Source: COV)

Table 3.3 shows at first stakeholders who have participated in promotional activities show a significant average increase in their attitude towards pig meat from Europe. Thus on average, stakeholders who participated in one of the promotional activities had a more positive attitude towards pig meat from Europe, compared to stakeholders who did not (yet) participate in a promotional activity. Next to this, we tested whether stakeholders who have participated in promotional activities show an average increase in awareness of the quality aspects. The results are mixed. Stakeholders who participated in one of the promotional activities were more aware of a few - but not all - qualities of pig meat from Europe, compared to stakeholders who did not (yet) participate in a promotional activity. Some of the differences are statistically significant, others are not. The largest significant average increase can be observed at 'European pig meat is free of residues', followed by 'Trustworthiness of European pig meat' and 'High safety of European pig meat'. The smallest significant average increase is referring to 'Measures are taken to make European pig meat safe.' 
Table 3.3 Attitude and quality aspects, across all countries (average on a 1-7 scale)

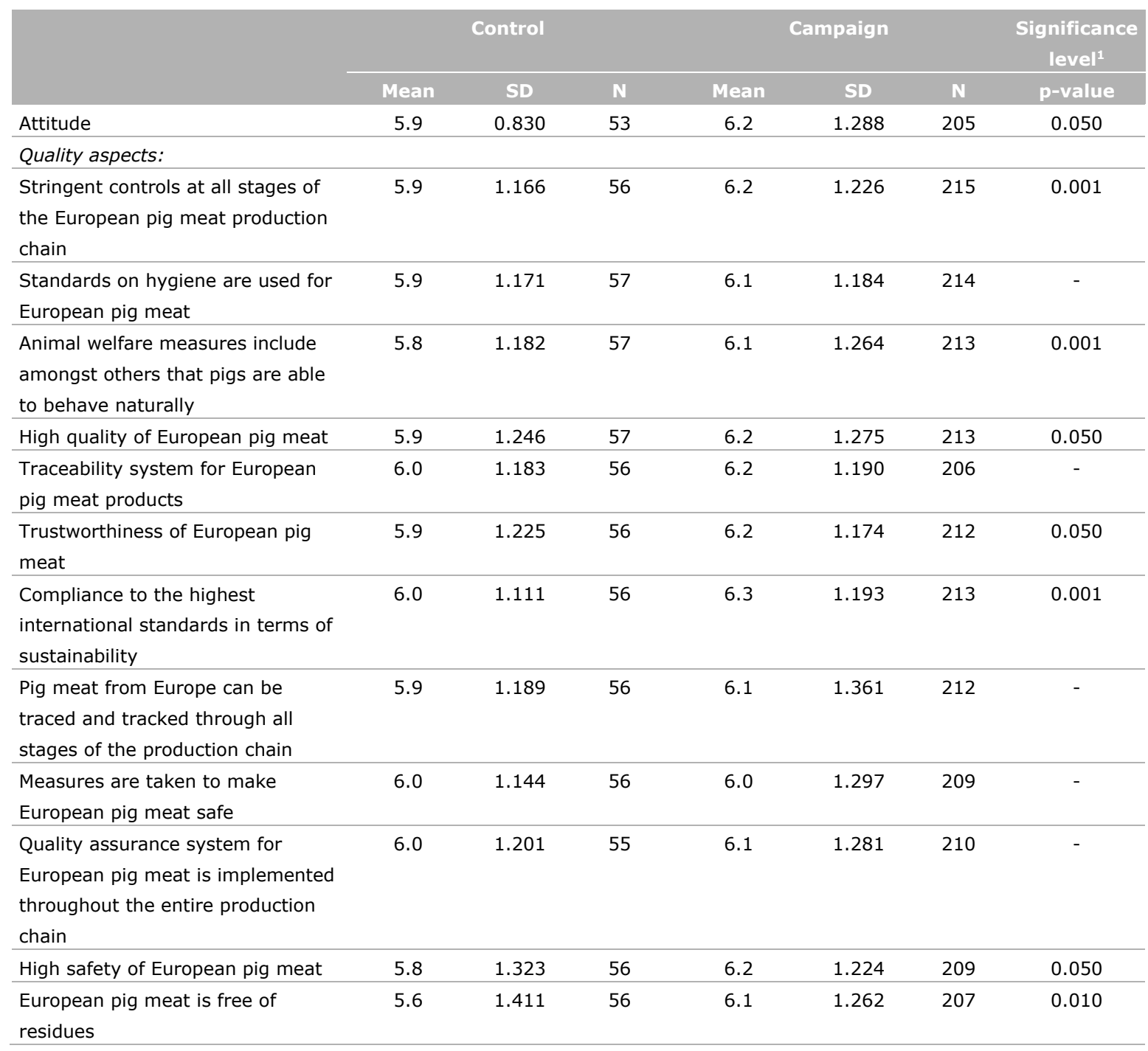

${ }^{1}$ one tail t-test

\subsection{China}

In China most respondents are male (64\%); between 20 and 59 years old (80\%) and they are employed as a trader or importer. Overall they rated the event they attended as quite good to excellent with 6.5 on average (1-7 scale).

Their attitude towards pig meat from Europe is on average quite positive (6.2), as are the average scores referring to the key messages of the Trusted Pork from Europe' promotion campaign. These figures are even slightly better, as Table 3.4 shows, in particular the key element 'safety'.

Table 3.4 Attitude and key messages, China (average on a 1-7 scale)

\begin{tabular}{|c|c|c|c|}
\hline China & Mean & SD & $\mathbf{N}$ \\
\hline Attitude & 6.2 & 1.23 & 162 \\
\hline Safety & 6.5 & 0.90 & 158 \\
\hline Animal welfare & 6.4 & 1.01 & 142 \\
\hline Quality & 6.4 & 1.14 & 153 \\
\hline
\end{tabular}


Respondents have rated statements concerning the qualities of pig meat from Europe. As Table 3.5 shows, all items are scored quite high in relation to the scale (1 to 7). This means, on average Chinese stakeholders are quite aware of the quality aspects of pig meat from Europe. In particular the items 'Trustworthiness of European pig meat' and 'Compliance to the highest international standards in terms of sustainability' rank highest.

Table 3.5 Quality aspects, China (average on a 1-7 scale)

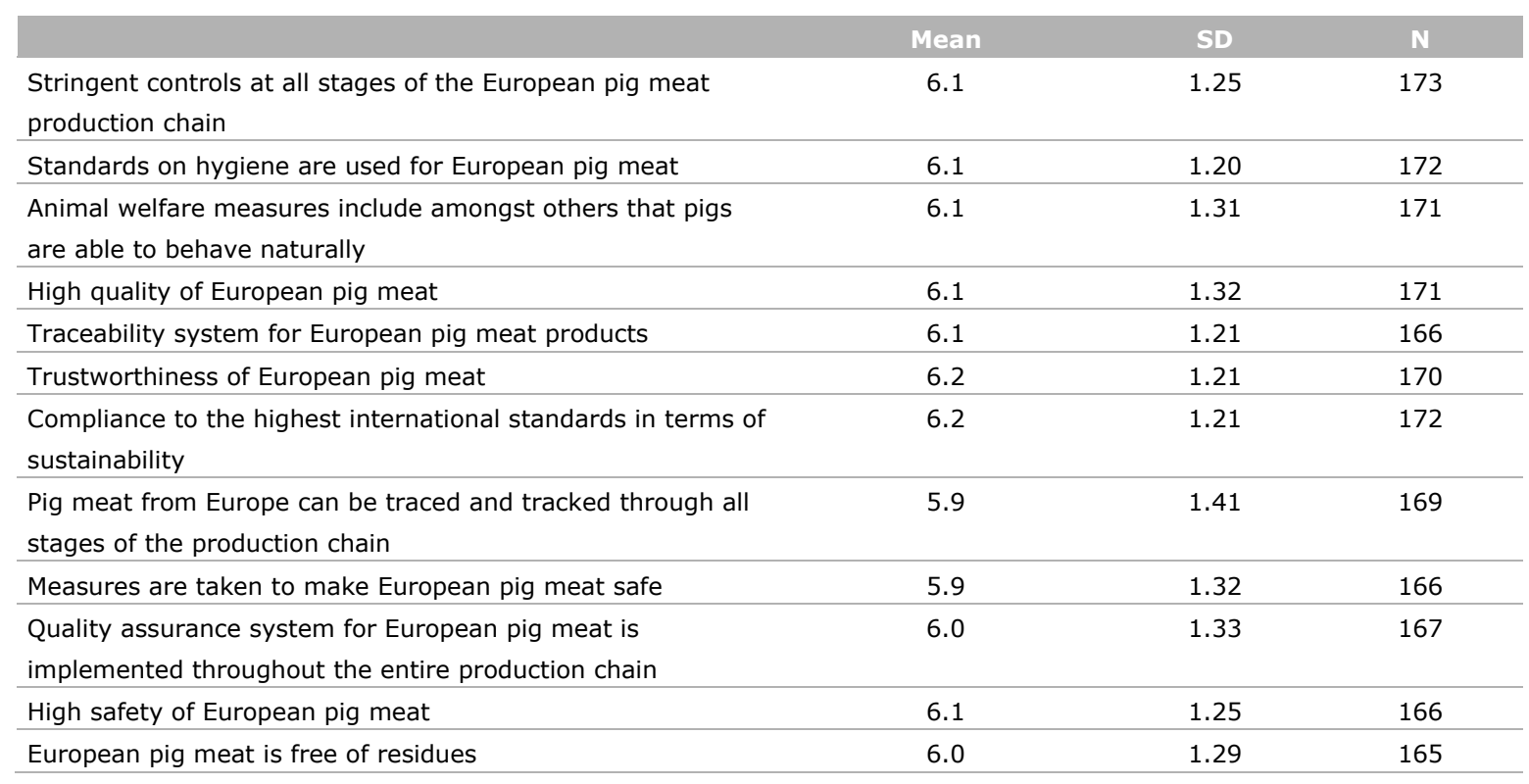

\subsection{Philippines}

In the Philippines most respondents are almost equally distributed in terms of gender, $47 \%$ is male and $53 \%$ is female. Most respondents (79\%) are between 20 and 59 years old and work as a trader or choose for the non-specified option. Overall they rated the event they attended as quite good to excellent with 6.2 on average (1-7 scale).

Their attitude towards pig meat from Europe is on average quite positive (6.3) as are the average scores referring to the key message of the Trusted Pork from Europe promotion campaign. These last mentioned figures are even slightly better in comparison with attitude as Table 3.6 shows, in particular the key element 'animal welfare'.

Table 3.6 Attitude and key messages, Philippines (average on a 1-7 scale)

\begin{tabular}{lccc} 
Philippines & Mean & SD & \\
Attitude & 6.3 & 1.24 & 30 \\
\hline Safety & 6.5 & 0.70 & 28 \\
\hline Sustainability & 6.5 & 0.70 & 28 \\
\hline Animal welfare & 6.6 & 0.70 & 27 \\
\hline Quality & 6.4 & 0.84 & 27 \\
\hline
\end{tabular}

Respondents have rated statements concerning the qualities of pig meat from Europe. As Table 3.7 shows, all items are scored quite high in relation to the scale ( 1 to 7 ). This means, on average stakeholders from the Philippines are quite aware of the quality aspects of pig meat from Europe. In particular the items 'Compliance to the highest international standards in terms of sustainability' and 'Pig meat from Europe can be traced and tracked through all stages of the production chain' rank highest. 
Table 3.7 Quality aspects, Philippines (average on a 1-7 scale)

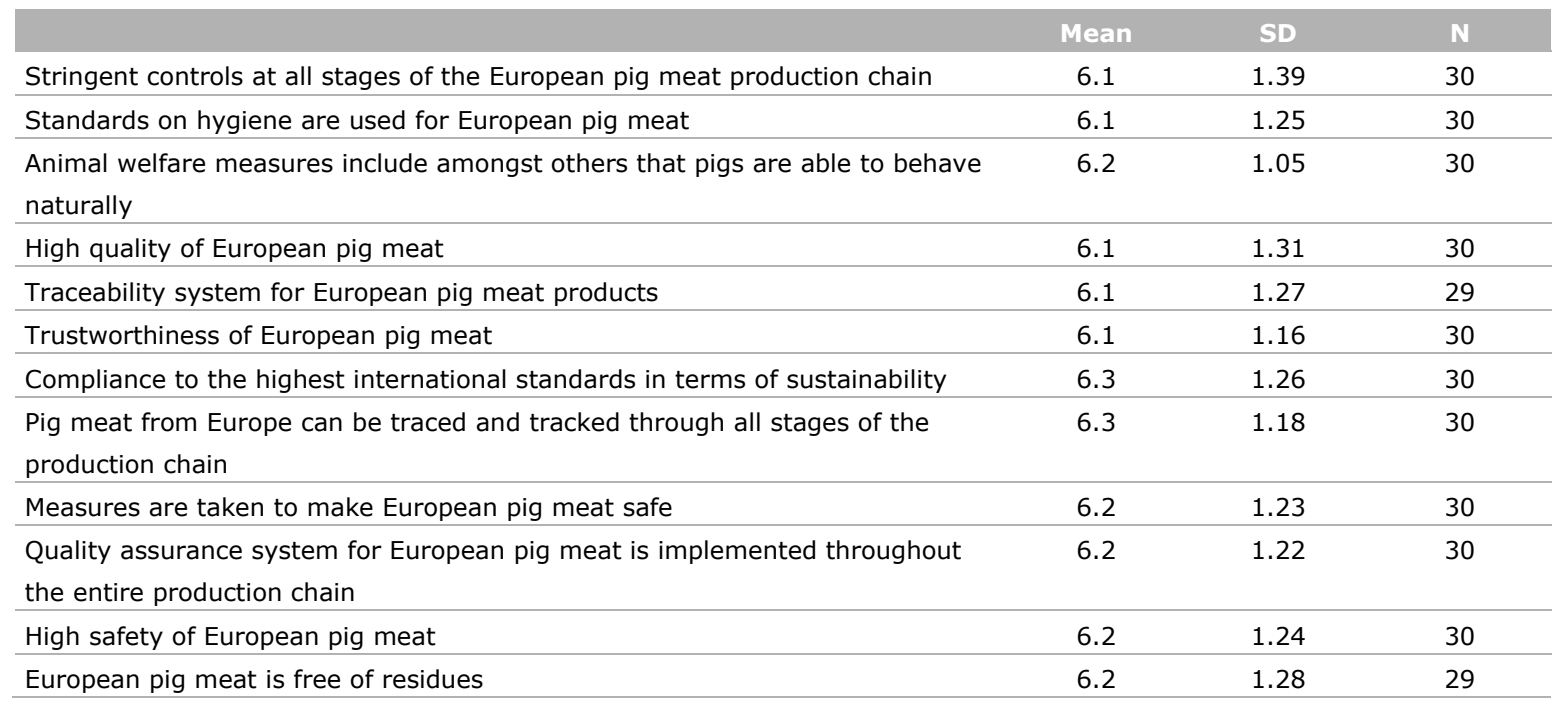

\subsection{Vietnam}

In Vietnam most respondents are female (67\%). Most respondents (78\%) are between 20 and 59 years old and work as an importer. Overall they rated the event they attended as quite good to excellent with 6.2 on average (1-7 scale).

Their attitude towards pig meat from Europe is on average quite positive (6.6) as are the average scores referring to the key message of the Trusted Pork from Europe promotion campaign. These last mentioned figures are even slightly better as 3.8 shows, in particular the key element 'quality'.

Table 3.8 Attitude and key messages, Vietnam (average on 1-7 scale)

\begin{tabular}{llrr} 
Vietnam & Mean & SD & N \\
Attitude & 6.1 & 1.61 & 24 \\
\hline Safety & 6.5 & 1.10 & 24 \\
\hline Sustainability & 6.5 & 1.01 & 23 \\
\hline Animal welfare & 6.4 & 0.99 & 23 \\
\hline Quality & 6.7 & 0.54 & 23 \\
\hline
\end{tabular}

Respondents have rated statements concerning the qualities of pig meat from Europe. As Table 3.9 shows, all items are scored quite high in relation to the scale (1 to 7). This means, on average stakeholders from Vietnam are quite aware of the quality aspects of pig meat from Europe. Several items rank highest, e.g. 'Standards on hygiene are used for European pig meat' and 'Trustworthiness of European pig meat'. 
Table 3.9 Quality aspects, Vietnam (average on a 1-7 scale)

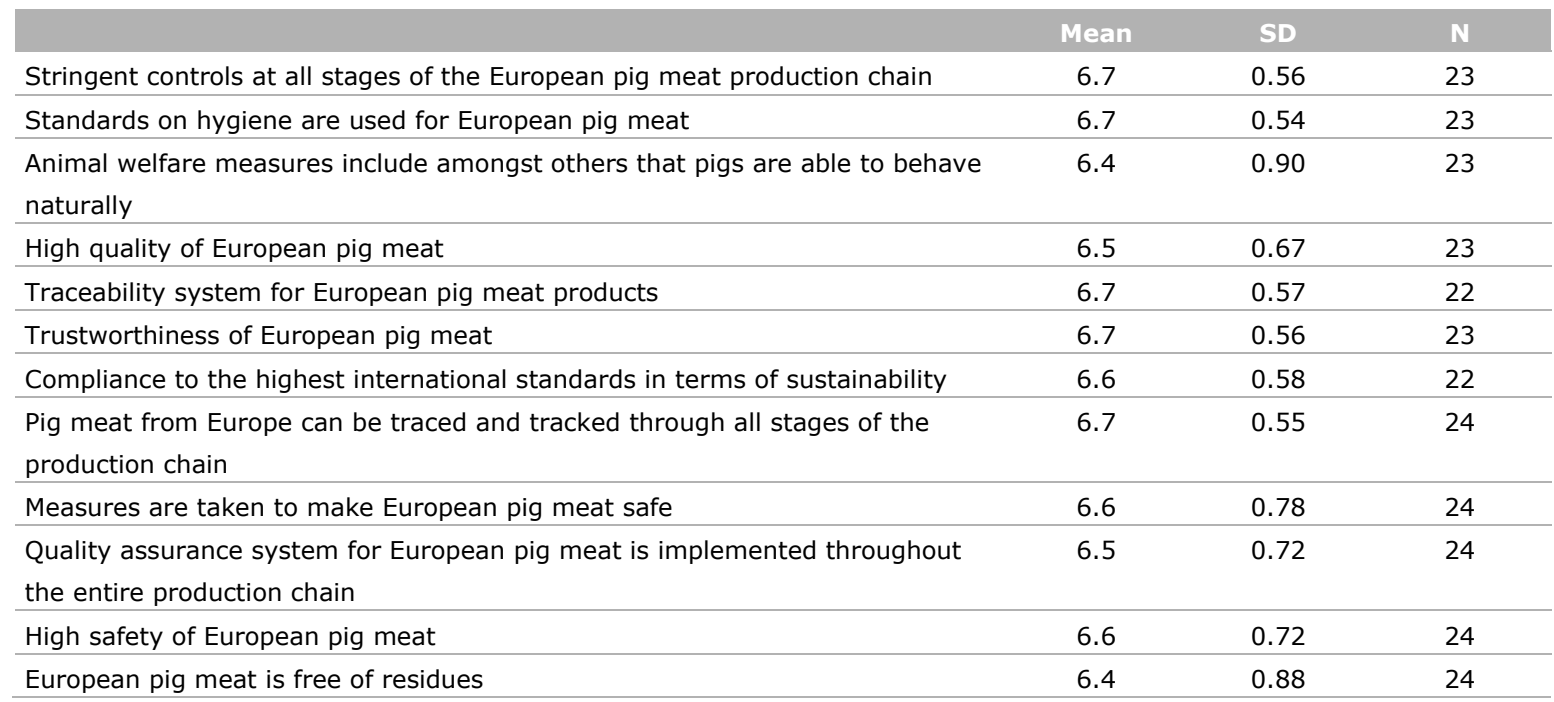




\section{Conclusions and discussion}

\subsection{Conclusions}

The Dutch Meat Association (COV) has initiated a promotion campaign in order to promote pig meat export from the European Union to countries in South East Asia. The Trusted Pork from Europe campaign ran from April 2017 until March 2020. The campaign's objectives are directed towards creating economic impact in sales to China, Philippines, Vietnam, Taiwan and Japan, and to create a higher awareness of the different quality aspects concerning pig meat from Europe among respective stakeholders. The study evaluates the campaign by measuring the degree to which these objectives were met. The conclusions are presented below.

Objective 1: Increasing the position of EU pig meat and expansion of the sales assortment The targeted countries have gained relevance for EU exporters, especially for frozen meat and offal. We cannot judge whether this is caused by the Trusted Pork from Europe promotion campaign, given the many other factors strongly influencing the world trade of pig meat, especially in the year 2019. See Section 4.2 for a further explanation. The results show an significant increase in the export of EU pig meat to the targeted countries, in particular China. From the analysis it can be concluded that the total export value of pig meat products to the five Asian destination countries has more than doubled over the period 2014-2019. The total export value amounted to $€ 7 b n$ in 2019, far higher than the $€ 2.5 b n$ in 2014. An export value of $€ 5 b n$ went to China alone.

Also the relevance of these countries in the EU export portfolio has increased between 2014 and 2019. For frozen meat the five destination countries took 55\% of the total EU28 export value in 2019, up from about 32\% in 2014. For lard and fat this increased from 9 to $29 \%$, and for offal from 36 to $70 \%$. Overall it can be concluded that between 2014 and 2019, the focus countries have gained relevance for EU exporters, especially for frozen meat and offal. For lard and fat the relative increase is evident as well, but in terms of total export value this product category is less important. For each of these three product categories, China is the largest, both in market share and increase of market share in total export value from the EU. For all product categories together, the market share of the five Asian destination countries in the total EU pig meat export value increased from $11 \%$ in 2014 to $24 \%$ in 2019. Also in volume terms the joint market share of the five countries in the EU pig meat export increased, from $13 \%$ in 2014 to $26 \%$ in 2019.

Based on trade data, it can be stated that the increased export resulted in an higher share of muscle meat (frozen and fresh) compared to lower value products (lard, fat and offal), both in volume and value percentage. This is supported by the interviewees, who stated some shift in the sales assortment: increasingly muscle products (category frozen) are being sold, although offal are also well demanded.

The sales value of lard, fat and offal together group, representing lower value products, traditionally exported to Asian destinations, increased by 2.5 times in 2019 compared to 2014 . Sales of muscle meat (frozen and fresh) in 2019 amounted to 2.9 times the value in 2014. In volume terms the lower value products increased by 1.8 times, but muscle meat by 2.7 times in 2019 compared to 2014 . It is concluded that the increased export resulted in a higher share of muscle meat (frozen and fresh) than of lower value products (lard, fat and offal), both in volume and value percentage. Similar to the former conclusion we want to emphasise that we cannot judge whether this is caused by the Trusted Pork from Europe promotion campaign or not, given the many other factors strongly influencing the world trade of pig meat, especially in the year 2019. 


\section{Objective 2: Expand business opportunities by increasing number of clients and the relationships' quality}

An increase in the number of clients could hardly be quantified. Having said so, most interviewees saw an increase in number of new clients per country. The number of new clients per company interviewed varied from zero to tens of clients in China. In Taiwan and the Philippines there were 'a few' new clients on average, and trade is preferentially done via middlemen/importers. In Vietnam hardly any new client was contracted, and in Japan the number of new clients differed among interviewees: zero, 'a few', to 'about ten'. All in all it can be concluded that the companies were rather successful in building new customer relationships, with the most new customers in China, followed by Japan, and Vietnam showing the lowest expansion of business opportunities in terms of number of new clients.

In general terms, activities like setting up a booth at several exhibitions, were seen as good opportunities to meet both existing customers and strengthen the relationship, and meet new prospects. The activities in the campaign contributed to a better understanding of quality aspects of European pig meat: safe, residue free, from a controlled production chain, traceable, hygienic production circumstances, sustainable and according to a European standard of animal welfare. Existing customers basically know these qualities already, but their awareness was raised, according to the interviewees. Plus new customers and prospects could be reached and explained these qualities, especially in focussed activities like network meetings, seminars and study tours. However, some interviewees doubted the effectiveness of network meetings and seminars, as it is a challenge to invite the persons who are most relevant for European exporters.

We asked the interviewees about their perceptions on sales opportunities in the destination countries. In the short term markets are very attractive. However, recovery of African Swine Fever is expected in a few years, and market opportunities in China are expected to become seriously reduced. The Philippines and Vietnam are seen as alternative sales market. Still, unique selling points will become even more relevant in the near future. Trust, the lead term of the promotion campaign, is then a prerequisite. In that perspective this term was perceived a good choice by the interviewees, although one respondent suggested that using this term would rather lead to doubting the actual trustworthiness of European pig meat.

It can be concluded that interviewees were happy with most of the activities, as it gave a good opportunity to show product and supply chain approach of European pig meat, and the campaign led to strengthened relationships with existing clients and formed a good basis for acquiring new clients. Given the market expectations for the next years, strengthening the market potential is essential for continuation of pig meat export to east Asian countries.

\section{Objective 3: Creating a higher level of awareness of the different qualities of EU pig meat} In this study we focus on whether a higher level of awareness has been realised, taking the communication campaign as a starting point. The data collected was limited in terms of number of completed surveys (particularly for the control group), consequently a statistical evaluation of developments in individual countries was unachievable. However, a post hoc power analysis showed that a statistical evaluation on a total level, in which the data of the different countries were combined, was possible with the number of completed surveys across countries for both the campaign group and control group.

In general we find that the campaign activities were appreciated by the stakeholders who participated. When asked, they rated the events very positive. Overall, the results show that stakeholders are positive about the promotion campaigns' key messages. On average the stakeholders believe pig meat from Europe is safe, sustainable, animal friendly and of high quality. The countries show some variation: on average, in China the key message element 'safety' is ranked highest, in the Philippines 'animal welfare' and in Vietnam 'quality'.

On average stakeholders who participated in one of the promotional activities had a more positive attitude towards pig meat from Europe, compared to stakeholders who did not (yet) participate in a promotional activity. Next to this, we tested whether stakeholders who have participated in promotional activities show an average increase in awareness about the quality aspects. The results 
are mixed. Stakeholders who participated in one of the promotional activities were more aware of a few - but not all - qualities of pig meat from Europe, compared to stakeholders who did not (yet) participate in a promotional activity. The largest significant average increase can be observed at 'European pig meat is free of residues', followed by 'Trustworthiness of European pig meat' and 'High safety of European pig meat'. The smallest significant average increase is referring to 'Measures are taken to make European pig meat safe.'

Thus, promotional activities that were part of the campaign appeared to lead to stakeholders becoming more aware of most types of quality aspects concerning European pig meat. As such, we find in general that stakeholders' awareness of European pig meat, in terms of attitude towards European pig meat and quality aspects, is higher among stakeholders who participated in a promotional activity, compared to who had not (yet) taken part in an activity - measured at the level of all countries combined (China, Philippines, Vietnam). Regarding the individual countries, respondents have rated statements concerning the quality aspects of pig meat from Europe. Based on the results we can conclude stakeholders are quite aware of the different quality aspects concerning pig meat from Europe, though we cannot measure whether this is caused by the communication campaign.

\subsection{Discussion}

Export volumes of pig meat to the South East Asian countries during the promotion campaign increased substantially. We cannot judge to what extent the campaign has influenced this, but given the massive impact of recent developments on the production and global pig meat trade patterns, we deem the effect of the campaign very limited. For instance, a massive outbreak of African Swine Fever in many countries worldwide occurred, as of 2019 in the five Asian destination countries. In China the pig population was reduced by about $50 \%$; in other countries to a smaller degree. All in all the world's pig population shrunk by at least $25 \%$, with extensive consequences for the world trade in pig meat. Moreover, recovery is likely to take several years (Jongeneel et al., in press). Other factors influencing the world trade in pig meat include currency exchange ratio fluctuations and tensions in the ChinaUSA relationship. Also the Covid-19 pandemic is affecting the global pig meat trade, however this only started late 2019 and its effect is likely to be relatively small, compared to the African Swine Fever outbreak (Jongeneel et al., in press).

However, given an expected change in the market situation in foreseeable future (some years) towards a rather tough market situation, it is necessary to be prepared and be well-known and esteemed as potential supplier of pig meat. From that perspective the promotion campaign might have been at the right time and with the right message towards customers in the East Asian countries. On a different note, other pig meat promotion campaigns were performed, partly overlapping with the Trusted Pork from Europe campaign. Therefore it is almost impossible to separate the effect of the campaign on the improved export opportunities. In addition, we recommend for further research and more insight to expand the set of countries which are subject to research and also include other, nontargeted countries as a comparison.

For the evaluation we measured the stakeholders' awareness regarding European pig meat. However, several methodological remarks should be taken into account. First, the average levels for stakeholders' attitudes towards European pig meat and their awareness of quality aspects was very high, in all countries but also in the (albeit small) control group of stakeholders. The latter point results in a so-called ceiling effect: because stakeholders' level of awareness regarding European pig meat is already very high, even irrespective of the promotion campaign, there is little room left for the campaign to increase awareness. Nonetheless, the campaign did lead to a statistically significant higher level of awareness among stakeholders who participated in a promotional activity, at the level of all countries combined (China, Vietnam, Philippines). On a related note, almost all respondents indicated to have high to very high levels of awareness, which leads to skewed data. For the dataanalyses, levels of skewness were checked, which indicated that the skewness levels were not too high to affect the data analysis. Second, there was quite a large dropout of respondents due to a sample of stakeholders who participated in a promotional activity but stated they had not heard of the promotion 
campaign. We did not include these respondents in the analysis, as inclusion would then not measure the effect of the promotional campaign itself anymore. While we can only speculate, it is possible that some stakeholders who entered the exhibition ground had already heard of the campaign from other stakeholders beforehand or already came across the campaign via other campaign activities.

Furthermore, certain stakeholders might have participated in an event on the fair (seminar, chef contest, product tasting), without noticing any communication materials that indicated the event they participated in was part of this promotional campaign, hence leading to their being unaware of the campaign even though they did participate in an event but ended up more aware of the quality aspect of EU pig meat. For future campaign evaluations, knowing why these stakeholders apparently did not hear of the promotion campaign, even though they participated in one of the promotional activities, can contribute in establishing a connection in the minds of stakeholders between the activity and the campaign and subsequently attribute effects to the promotion campaign. In addition, attention should be paid to get enough respondents in both the experimental group and the control group or consider another method for evaluation or choose an alternative design for evaluating. Third, future research can explore which specific aspects of the campaign led to a higher level of awareness of European pig meat among stakeholders. With the current numbers of respondents, statistical analyses were not possible at the level of individual countries, but also at the level of individual activities/components of the promotion campaign. It can be beneficial to know more about which specific promotional activities lead to the highest increase in awareness, as future promotion campaigns can then mainly focus on the most effective types of activities to increase awareness among stakeholders. 


\section{References and websites}

Ajzen, I. (1991). The theory of planned behavior. Organizational Behavior and Human Decision Processes, 50(2), 179-211.

Flynn and Goldsmith (1999). A Short, Reliable Measure of Subjective Knowledge. Journal of Business Research 46(1), 57-66

Hoste, R., 2020. International comparison of pig production costs 2018; Results of InterPIG. Wageningen, Wageningen Economic Research, Report 2020-007. http://edepot.wur.nl/511876.

Jongeneel, R., A.R. Gonzalez-Martinez and R. Hoste (in press). An uncertain fate for the EU pig sector: Potential consequences of the 2019 African Swine Fever outbreak in East Asia. Submitted to EuroChoices.

Lavidge, R. and G. Steiner (1961). A Model of Predictive Measurements of Advertising Effectiveness. Journal of Marketing, 25, 59-62

Onwezen, M.C., G. Antonides and J. Bartels (2013). The Norm Activation Model: An exploration of the functions of anticipated pride and guilt in environmental behaviour. Journal of Economic Psychology, 49, 141-153. 


\section{Appendix 1 Comext codes and product categories}

\begin{tabular}{ll}
\hline Product code & Category \\
020311 - Fresh or chilled carcases and $1 / 2$ carcases of swine & Fresh meat \\
\hline 020312 - Fresh or chilled hams, shoulders and cuts thereof of swine, unboned & Fresh meat \\
\hline 020319 - Fresh or chilled meat of swine (excl. carcases and $1 / 2$ carcases, and hams, shoulders and cu & Fresh meat \\
\hline 020321 - Frozen carcases and $1 / 2$ carcases of swine & Frozen meat \\
\hline 020322 - Frozen hams, shoulders and cuts thereof, unboned & Frozen meat \\
\hline 020329 - Frozen meat of swine (excl. carcases and $1 / 2$ carcases, and hams, shoulders and cuts thereof & Frozen meat \\
\hline 020630 - Fresh or chilled edible offal of swine & Offal \\
\hline 020641 - Frozen edible livers of swine & Offal \\
\hline 020649 - Edible offal of swine, frozen (excl. livers) & Offal \\
\hline 020900 - Pig fat, free of lean meat and poultry fat not rendered, fresh, chilled, frozen, salted, in & Lard, fat \\
\hline 020910 - Pig fat, free of lean meat, not rendered or otherwise extracted, fresh, chilled, frozen, sa & Lard, fat \\
\hline 021011 - Unboned hams, shoulders and cuts thereof of swine, salted, in brine, dried or smoked & Processed \\
\hline 021019 - Meat of swine, salted, in brine, dried or smoked (excl. unboned hams, shoulders and cuts th & Processed \\
\hline 150100 - Lard; other pig fat and poultry fat, rendered, whether or not pressed or solvent-extracted & Lard, fat \\
\hline 150110 - Lard, rendered or otherwise extracted (excl. lard stearin and lard oil) & Lard, fat \\
\hline 150120 - Pig fat, rendered or otherwise extracted (excl. lard) & Lard, fat \\
\hline 160100 - Sausages and similar products, of meat, offal or blood; food preparations based on these pr & Processed
\end{tabular}


Wageningen Economic Research P.O. Box 29703

2502 LS The Hague

The Netherlands

$\mathrm{T}+31(0) 703358330$

E communications.ssg@wur.nl

www.wur.eu/economic-research

Wageningen Economic Research REPORT

2020-050
The mission of Wageningen University \& Research is "To explore the potential of nature to improve the quality of life". Under the banner Wageningen University \& Research, Wageningen University and the specialised research institutes of the Wageningen Research Foundation have joined forces in contributing to finding solutions to important questions in the domain of healthy food and living environment. With its roughly 30 branches, 5,000 employees and 12,000 students, Wageningen University \& Research is one of the leading organisations in its domain. The unique Wageningen approach lies in its integrated approach to issues and the collaboration between different disciplines.

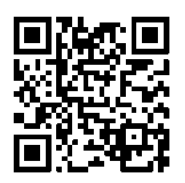





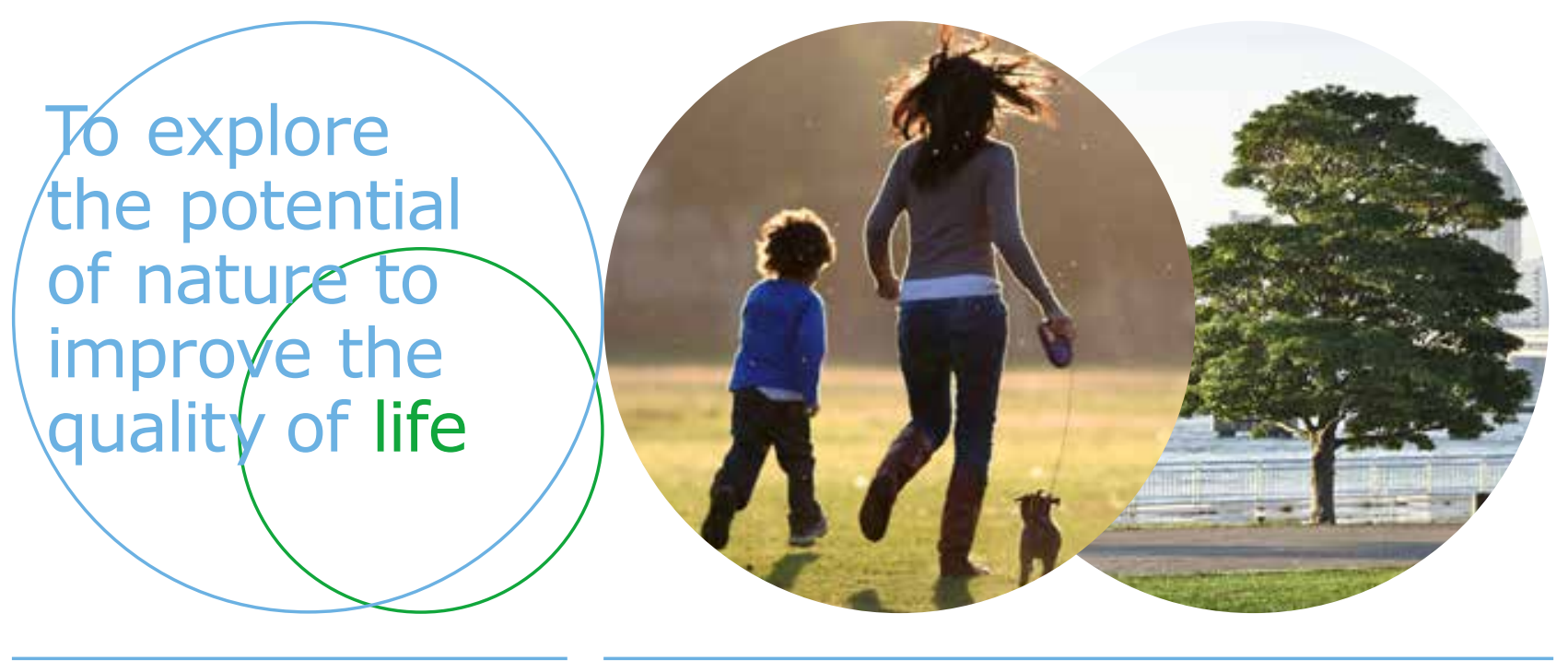

Wageningen Economic Research P.O. Box 29703

2502 LS Den Haag

The Netherlands

T+31(0)7033583 30

E communications.ssg@wur.nl

www.wur.eu/economic-research

Report 2020-050

ISBN 978-94-6395-429-7
The mission of Wageningen University \& Research is "To explore the potential of nature to improve the quality of life". Under the banner Wageningen University \& Research, Wageningen University and the specialised research institutes of the Wageningen Research Foundation have joined forces in contributing to finding solutions to important questions in the domain of healthy food and living environment. With its roughly 30 branches, 5,000 employees and 12,000 students, Wageningen University \& Research is one of the leading organisations in its domain. The unique Wageningen approach lies in its integrated approach to issues and the collaboration between different disciplines. 